Review

\title{
A Review of Fabrication Technologies for Carbon Electrode-Based Micro-Supercapacitors
}

\author{
Veerle Vandeginste
}

Citation: Vandeginste, V. A Review of Fabrication Technologies for Carbon Electrode-Based Micro-Supercapacitors. Appl. Sci. 2022, 12, 862. https://doi.org/ 10.3390/app12020862

Academic Editor: Valentina Belova

Received: 23 December 2021

Accepted: 13 January 2022

Published: 14 January 2022

Publisher's Note: MDPI stays neutral with regard to jurisdictional claims in published maps and institutional affiliations.

Copyright: (C) 2022 by the author. Licensee MDPI, Basel, Switzerland. This article is an open access article distributed under the terms and conditions of the Creative Commons Attribution (CC BY) license (https:// creativecommons.org/licenses/by/ $4.0 /)$.
Department of Materials Engineering, KU Leuven Campus Bruges, 8200 Bruges, Belgium; veerle.vandeginste@kuleuven.be

\begin{abstract}
The very fast evolution in wearable electronics drives the need for energy storage microdevices, which have to be flexible. Micro-supercapacitors are of high interest because of their high power density, long cycle lifetime and fast charge and discharge. Recent developments on microsupercapacitors focus on improving the energy density, overall electrochemical performance, and mechanical properties. In this review, the different types of micro-supercapacitors and configurations are briefly introduced. Then, the advances in carbon electrode materials are presented, including activated carbon, carbon nanotubes, graphene, onion-like carbon, and carbide-derived carbon. The different types of electrolytes used in studies on micro-supercapacitors are also treated, including aqueous, organic, ionic liquid, solid-state, and quasi-solid-state electrolytes. Furthermore, the latest developments in fabrication techniques for micro-supercapacitors, such as different deposition, coating, etching, and printing technologies, are discussed in this review on carbon electrode-based micro-supercapacitors.
\end{abstract}

Keywords: carbon; energy storage; micro-machining; supercapacitor; thin film; wearable electronics

\section{Introduction}

The last decades have seen a tremendously fast evolution in technology of electronics [1]. Importantly, advances in nanotechnology have facilitated the ever further miniaturization of electronic devices [2,3]. The progress in wearable electronics also drives a huge need for the development of wearable energy devices to power those electronics [4-7] for applications, such as human health monitoring [8,9], intelligent electronic skins [10-13], foldable displays [14-16], and medical microdevices [17,18]. Batteries and supercapacitors are commonly used as energy storage units, but they are generally bulky and rigid, which is not ideal for wearable devices [19-22]. Therefore, efforts are focused on the development of flexible and very thin batteries and supercapacitors [23-29]. There are a few recent review papers on the advances in materials for supercapacitors [30-32]; however, a comprehensive review on the fabrication technologies for carbon electrode-based micro-supercapacitors is lacking.

Batteries and supercapacitors have different performance properties (Figure 1). Batteries have the advantage of high energy density $[33,34]$, whereas supercapacitors have the advantages of ultrahigh areal power density (more than $10 \mathrm{~kW}$ per $\mathrm{kg}$ ), long cycle lifetime (millions of cycles), and fast charge and discharge time (seconds) $[35,36]$. The charge in supercapacitors is limited to the surface of the electrode materials, so the energy density of supercapacitors is still limited to about 5 to $20 \mathrm{Wh}$ per $\mathrm{kg}$ [37-39]. Thus, supercapacitors fill the gap between batteries and aluminium electrolytic capacitors [40,41]. 


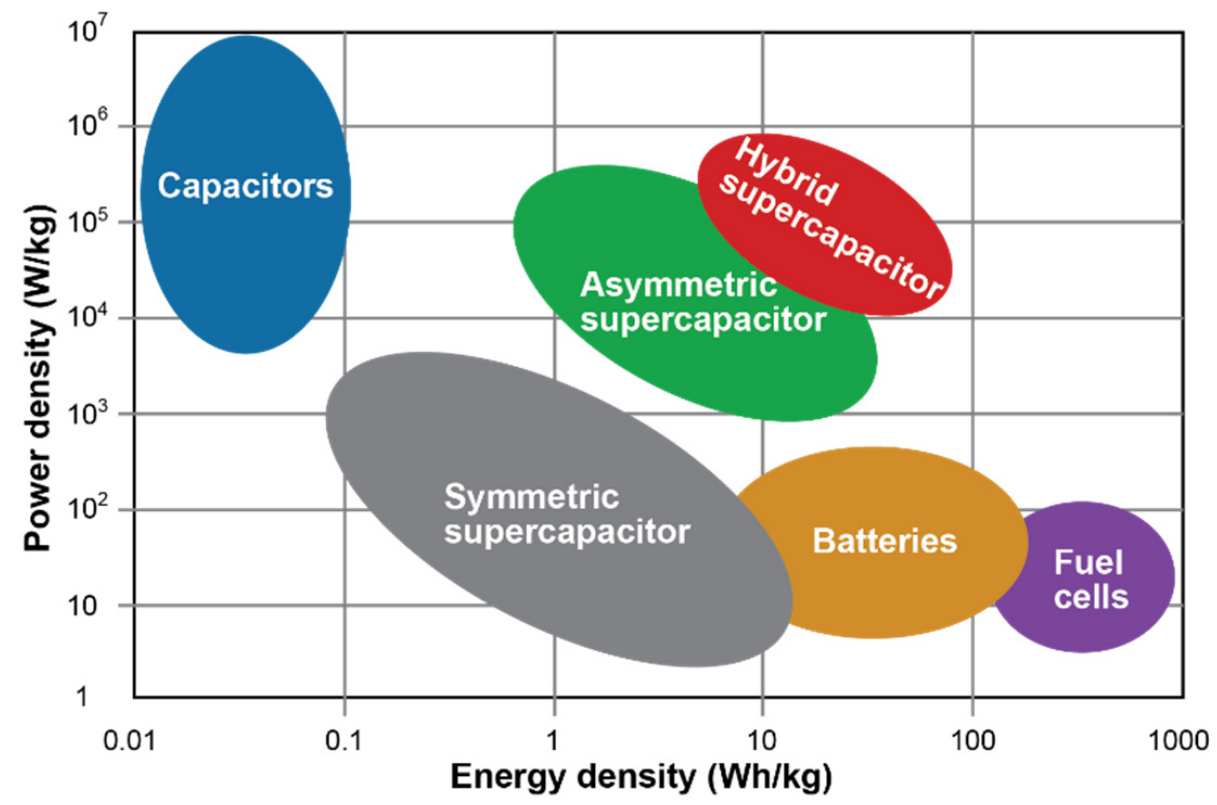

Figure 1. Ragone plot, showing power density versus energy density, for different types of energy storage materials.

There are three types of supercapacitors based on the charge storage mechanism (Figure 2). The first type is the electric double layer capacitor (EDLC), which does not involve a chemical oxidation-reduction reaction but rather the accumulation of electrostatic charges at the electrode/electrolyte interface upon an applied voltage [42]. Charges are stored by ion diffusion from the electrolyte into the pores of the electrode of opposite charge across the separator, based on the attraction force between opposite charges, resulting in physical adsorption $[41,43]$. The concentration of the electrolyte remains constant, and there are no volumetric or morphological changes with charging or discharging, so a very long cycle lifetime can be achieved. An EDLC supercapacitor has high power density but low specific capacitance [44]. The second type is the pseudocapacitor, which involves fast reversible redox reactions (faradaic processes, providing high energy density) between the electrode active materials and electrolytes at the electrode surface and the near-surface $[45,46]$. There are three main mechanisms of pseudocapacitors, namely: (i) reversible adsorption, (ii) redox reaction in metal oxides, and (iii) reversible doping/de-doping electrochemical processes in conductive polymer-based electrodes. Pseudocapacitors have high capacitance but low power density and cycle lifetime [47]. The third type is the hybrid supercapacitor, which uses both faradaic and non-faradaic processes to store charge [48]. Hybrid supercapacitors use EDLC type materials as the conductive backbone for pseudocapacitive materials with the aim of enhancing the electrochemical performance of the system [48].

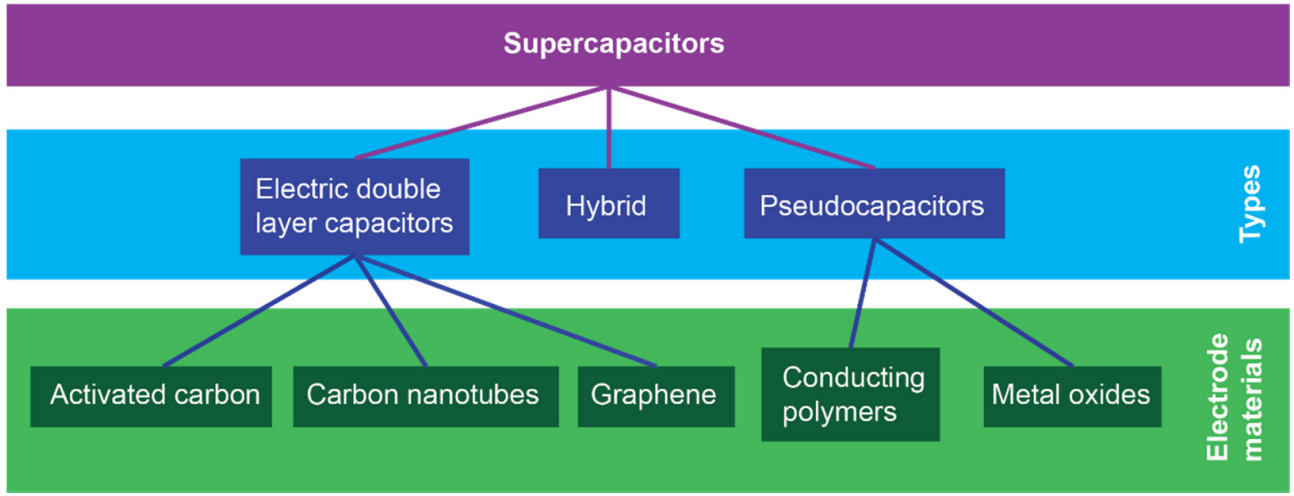

Figure 2. Diagram of the different types of supercapacitors and their main electrode materials. 
This review paper on fabrication technologies for carbon electrode-based microsupercapacitors is organized as follows. First, the micro-supercapacitor configurations are briefly described. Then, the different types of carbon materials used for electrodes in microsupercapacitors are presented, followed by the different types of electrolytes. Subsequently, a wide range of fabrication technologies for micro-supercapacitors is discussed, including several deposition, coating, etching, and printing methods. Finally, several challenges and future perspectives are highlighted, followed by a conclusion.

\section{Micro-Supercapacitor Configuration}

A conventional EDLC supercapacitor has a symmetric configuration with current collectors at the sides, as well as the electrode substrate and electrolyte, which are separated on both sides by the ionic conductor separator. For applications such as wearable power sources (where flexibility or stretchability may be required) and on-chip microelectronics, micro-supercapacitors are needed. In particular, thin film supercapacitors have very fast physical and chemical processes during charge storage due to the short ion transport distances [49]. These micro-supercapacitors can be fully charged or discharged within seconds. They have a long cycle lifetime, and they provide ultrahigh areal power density. The configuration of micro-supercapacitors with thin film electrodes can be divided into two main groups: (i) stacking (or sandwich) configuration and (ii) in-plane interdigitated configuration (Figure 3). Still, fibre shaped micro-supercapacitors have also been described in studies, and they could be considered as a third type, based on the device dimension [50].

The overall performance of the supercapacitor is strongly determined by the structural design of the electrode [51]. Carbon-based supercapacitors are the most common EDLC supercapacitors because of their high thermal and electrochemical stability, low cost, good electrical conductivity, controlled porosity, and appropriate active sites [52]. To achieve a supercapacitor with high capacitance, carbon electrodes need to have a controlled pore structure, a large specific surface area, and adequate surface functional groups [53]. The electrolytes in the supercapacitor are also important. Notably, to achieve a supercapacitor with high operating voltage, the carbon materials with modified surface chemistry need to be combined with electrolytes with good chemical and electrochemical stability for good kinetic stability [54]. Moreover, a high energy supercapacitor also requires appropriate cell design and engineering [55].

\section{Stacking supercapacitor}

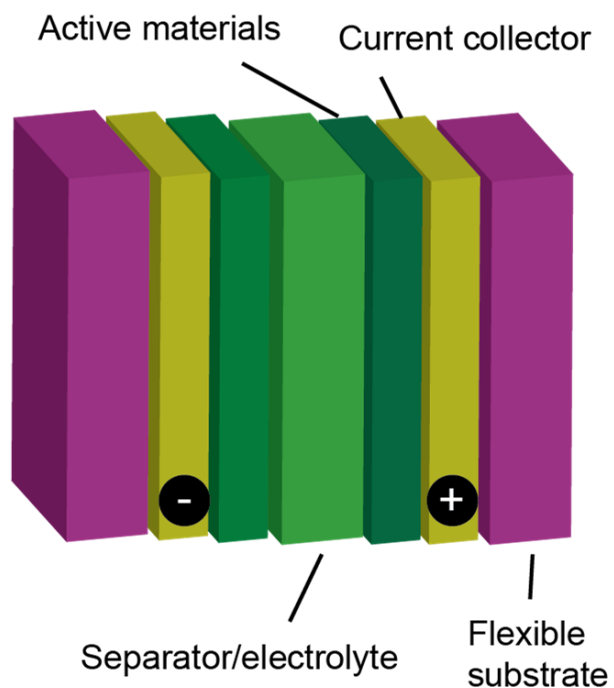

\section{In-plane supercapacitor}

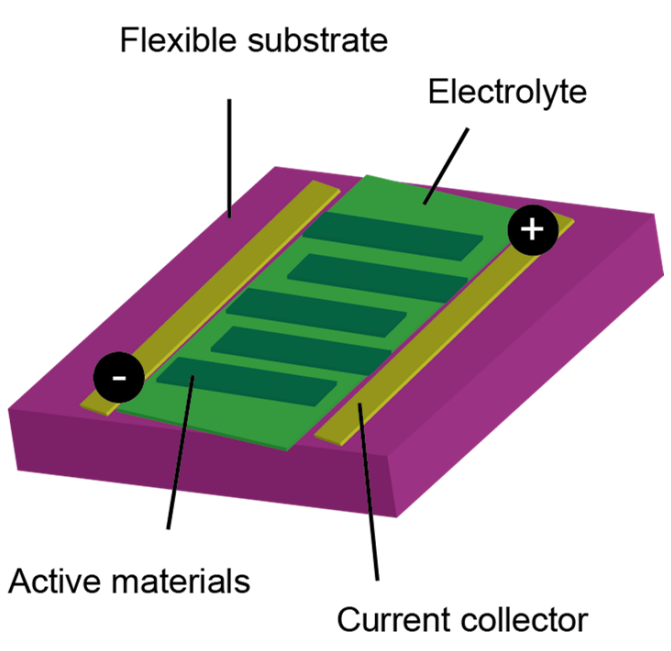

Figure 3. Schematic of the types of configurations of micro-supercapacitors: stacking (left) and in-plane (right). 


\section{Micro-Supercapacitor Carbon Electrodes}

Electrodes in thin film supercapacitors are made with a layer of active material that is only a few nanometres to several micrometres thick [56]. Carbon-based materials are generally used as electrodes in EDLC supercapacitors, as they satisfy the electrode requirements, although they suffer from low specific capacitance. Various carbon materials have been used, such as activated carbon [57], templated carbon [58], carbon nanotubes [59], graphene [60], carbon onions [61], and carbide-derived carbon [62]. These carbon materials have a high surface area, and thus, they can provide high specific energy and power. They have a lower cost in comparison to other materials, but their synthesis method may be more sophisticated. The morphology of the electrode material is key as it determines the interface and thus, influences the electrochemical performance. The energy storage capacity of nanoporous carbon electrodes can be increased by matching the average pore size to the bare ion diameter because desolvation of the ions in aqueous or organic electrolytes results in a more space-efficient arrangement of ions within the nanopores [63]. Other methods to improve the energy storage capacity of supercapacitors is to use ionic liquids [58], redox electrolytes [64], or the addition of redox-active materials, such as metal oxides [65] or heteroatom doping [66].

\subsection{Activated Carbon}

Activated carbon has a large specific surface area, complex porous structure, good electrical conductivity, high electrochemical stability, and it is relatively inexpensive. The disadvantages are that they have generally poor mechanical properties and need metal current collectors. Activated carbon (fibres) with large specific surface area and high specific capacitance are synthesized by carbonization and activation (physical, chemical, or a combination of both), for example, by $\mathrm{KOH}$ chemical activation and fluorination treatment [67], or phosphoric acid pre-impregnation and $\mathrm{CO}_{2}$ activation [68].

The conductivity of thin film electrodes can be increased by doping activated carbon with, for example, graphene oxide [69], carbon nanotubes [70], polypyrrole [71], or silver nanowires [72]. Doping activated carbon film electrode with $500 \mathrm{~nm}$ silver nanowires, fabricated using ultrasonic spray coating, resulted in an increase in the specific capacitance by $39 \%$ to $258 \mathrm{~F} / \mathrm{g}$ [72]. In a similar study, activated carbon was doped with silver nanowires, with $\mathrm{NiO}-\mathrm{Co}_{3} \mathrm{O}_{4}$ nanocomposites (produced via a hydrothermal method), which increases the specific capacitance of ultrasonic spray coated thin film supercapacitors to $707 \mathrm{~F} / \mathrm{g}$, and $93 \%$ of the capacitance remained even after 5000 cycles [73]. Electrodes of activated carbon fibres with well-aligned tin oxynitride nanorod arrays have shown a high specific capacitance of $673 \mathrm{~F} / \mathrm{g}$ at $1 \mathrm{~A} / \mathrm{g}$ and a cycling stability of $99 \%$ at $5 \mathrm{~A} / \mathrm{g}$ for 2000 cycles in $1 \mathrm{M} \mathrm{H}_{2} \mathrm{SO}_{4}$ electrolyte [74]. Activated carbon was doped with $\mathrm{MnO}_{2}$ and silver nanowires in order to improve the conductivity of the thin film electrode, resulting in a specific capacitance of $1021 \mathrm{~F} / \mathrm{g}$, a 325\% increase from the undoped activated carbon [75]. Another recent study presented the direct fabrication of hierarchical porous carbon/silicon carbide (HPC/SiC) composite from bamboo waste raw biomass via a facile method [76]. In this way, hybrid electrodes are made by combining semiconductors in order to overcome the drawback of the limited electrical conductivity of porous carbon. The specific capacitance of the HPC/SiC composite was $234 \mathrm{~F} / \mathrm{g}$ at a current density of $1 \mathrm{~A} / \mathrm{g}$ [76].

\subsection{Carbon Nanotubes}

Carbon nanotubes have a high surface area, unique internal structure, low density, excellent electrical conductivity, mechanical properties, and thermal and chemical stability. They are synthesized through decomposition of certain hydrocarbons and manipulation to achieve nanostructures such as single-walled carbon nanotubes. The aspect ratio of carbon nanotube electrodes influences the operational speed of micro-supercapacitors, with an aspect ratio increase from 0.2 to 7 , resulting in a nonlinear decrease in the relaxation time constant from 85 to about $0.5 \mathrm{~ms}$ [77]. 
Single-walled carbon nanotube thin films have been produced by vacuum filtration with subsequent stamping, with electrodeposition of cobalt hydroxide nanoflakes, which have excellent structural stability. The specific capacitance of these thin film supercapacitor electrodes was $314 \mathrm{~F} / \mathrm{g}$ [78]. Nickel hydroxide thin film electrodes were doped with carbon nanotubes and graphene oxide to improve the electrochemical properties. The doped electrode had a capacity of $430 \mathrm{mAh} / \mathrm{g}$ at a current density of $5 \mathrm{~A} / \mathrm{g}$, and this was still at 75\% after 1000 cycles [79]. Composites of carbon nanotubes with MXene were fabricated via photolithography, followed by vacuum filtration, for on-chip micro-supercapacitors. These layer-by-layer assemblies provided flexible layered channels and controllable electronic structures for electrolyte ion diffusion, and the areal capacitance was $61 \mathrm{mF} / \mathrm{cm}^{2}$ at a current density of $0.5 \mathrm{~mA} / \mathrm{cm}^{2}$ [80]. Fully stretchable micro-supercapacitors that were produced with oxidized single-walled carbon nanotubes and polyvinyl alcohol electrodes had a double layer capacitance of $20 \mathrm{mF} / \mathrm{cm}^{2}$ at $0.1 \mathrm{~mA} / \mathrm{cm}^{2}$ [81]. High energy density ultrathin highly aligned carbon nanotubes sheet supercapacitors were fabricated with interdigitated electrode planar configuration (Figure 4). Such devices with 50 layers, only $300 \mathrm{~nm}$ thick in total, had an energy density of $10.5 \mathrm{mWh} / \mathrm{cm}^{3}$ and a power density of $19 \mathrm{~W} / \mathrm{cm}^{3}$ [82].

\subsection{Graphene}

Graphene is a one-atom thick planar sheet of $\mathrm{sp}^{2}$ bonded carbon atoms that are arranged in a closely packed honeycomb crystal lattice. It has excellent electrical, mechanical, and morphological properties, as well as good thermal and chemical stability. Graphene can be made via a hydrothermal method.

Quasi-solid-state micro-supercapacitors were fabricated with cellular graphene film and polyvinyl alcohol $/ \mathrm{H}_{3} \mathrm{PO}_{4}$ (Figure 5) and show excellent electrochemical performance [83]. Similarly, such flexible electrolyte was used with graphene fibre electrodes, produced by electrochemical exfoliation of graphite foil thin strips, which exhibited a capacitance of about $248 \mathrm{mF} / \mathrm{cm}^{2}$ at about $2 \mathrm{~mA} / \mathrm{cm}^{2}$ [84]. Graphene structures were also produced using chemical vapour deposition to construct flexible micro-supercapacitors with excellent cycling stability and a high areal capacitance of $1.5 \mathrm{mF} / \mathrm{cm}^{2}$ at a scan rate of $10 \mathrm{~V} / \mathrm{s}$ [85]. Ultralong cycle life was achieved for micro-supercapacitors fabricated with laser irradiated graphene, with $100 \%$ retention of the initial capacitance even after 100,000 cycles [86]. Electrodes of graphene-coated copper foil with ruthenium oxide, deposited by cathodic electroplating, were fabricated for flexible supercapacitors, and they have a specific capacitance of $1561 \mathrm{~F} / \mathrm{g}$ at a scan rate of $5 \mathrm{mV} / \mathrm{s}$ and a high energy density of about $13 \mathrm{Wh} / \mathrm{kg}$ at a power density of about $21 \mathrm{~kW} / \mathrm{kg}$ [87]. Graphene was doped with fluorine to increase the specific capacitance, and a composite was made by combination with nanoscale carbidederived carbon, which has a high specific surface area and hierarchical pore structure. The specific capacitance of this composite in aqueous electrolyte was $321 \mathrm{~F} / \mathrm{g}$ at a scan rate of $5 \mathrm{mV} / \mathrm{s}$ [88]. Planar integrated systems of micro-supercapacitors were made with 2D hierarchical ordered dual-mesoporous polypyrrole/graphene nanosheets, with a large surface area of $112 \mathrm{~m}^{2} / \mathrm{g}$, and capacitance of $376 \mathrm{~F} / \mathrm{g}$ at $1 \mathrm{mV} / \mathrm{s}$ [89]. 


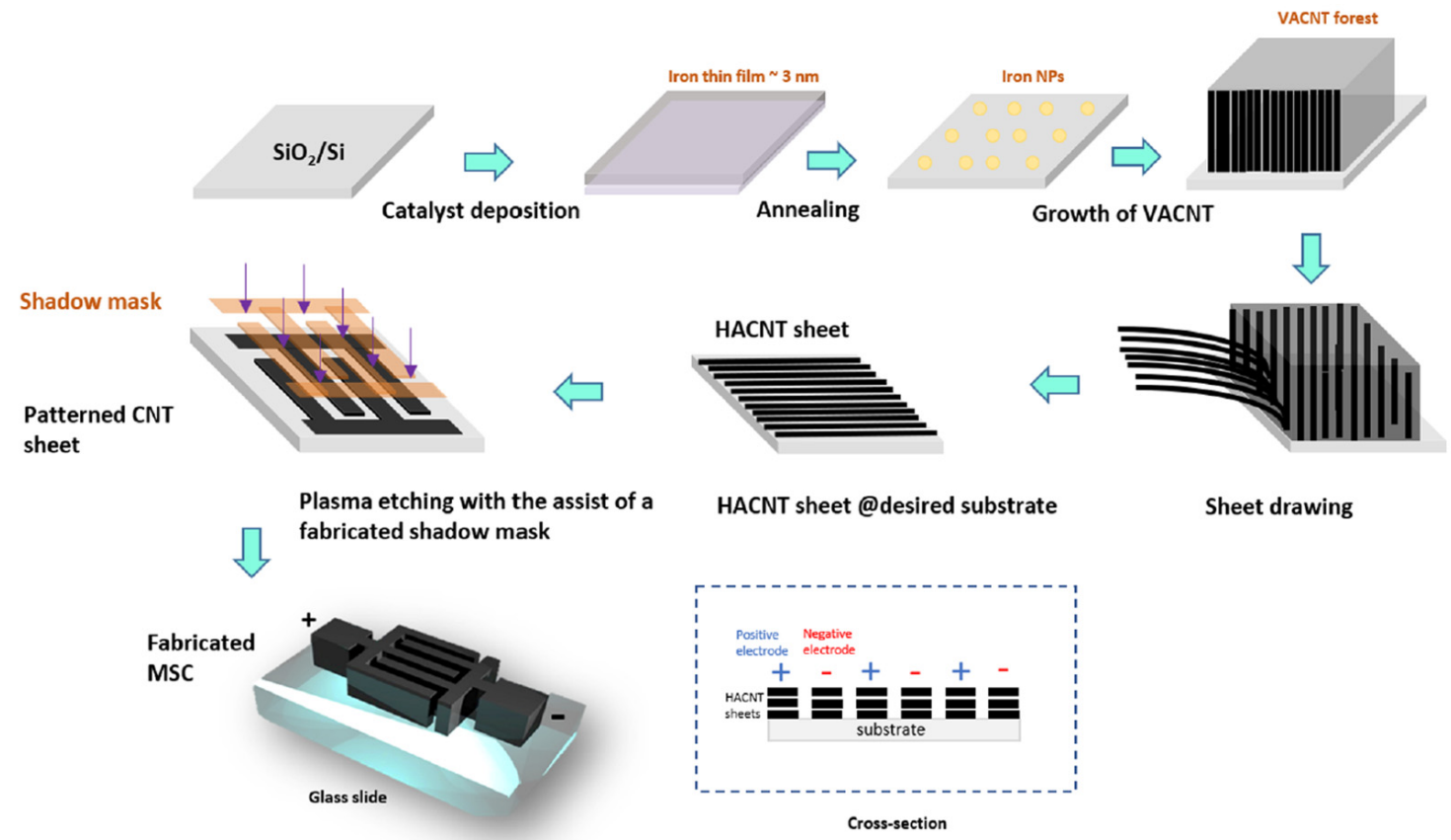

Figure 4. Work flow diagram of the fabrication process of highly aligned carbon nanotubes. Figure reprinted with permission from Dousti et al. [82]. Copyright 2020 American Chemical Society.

a
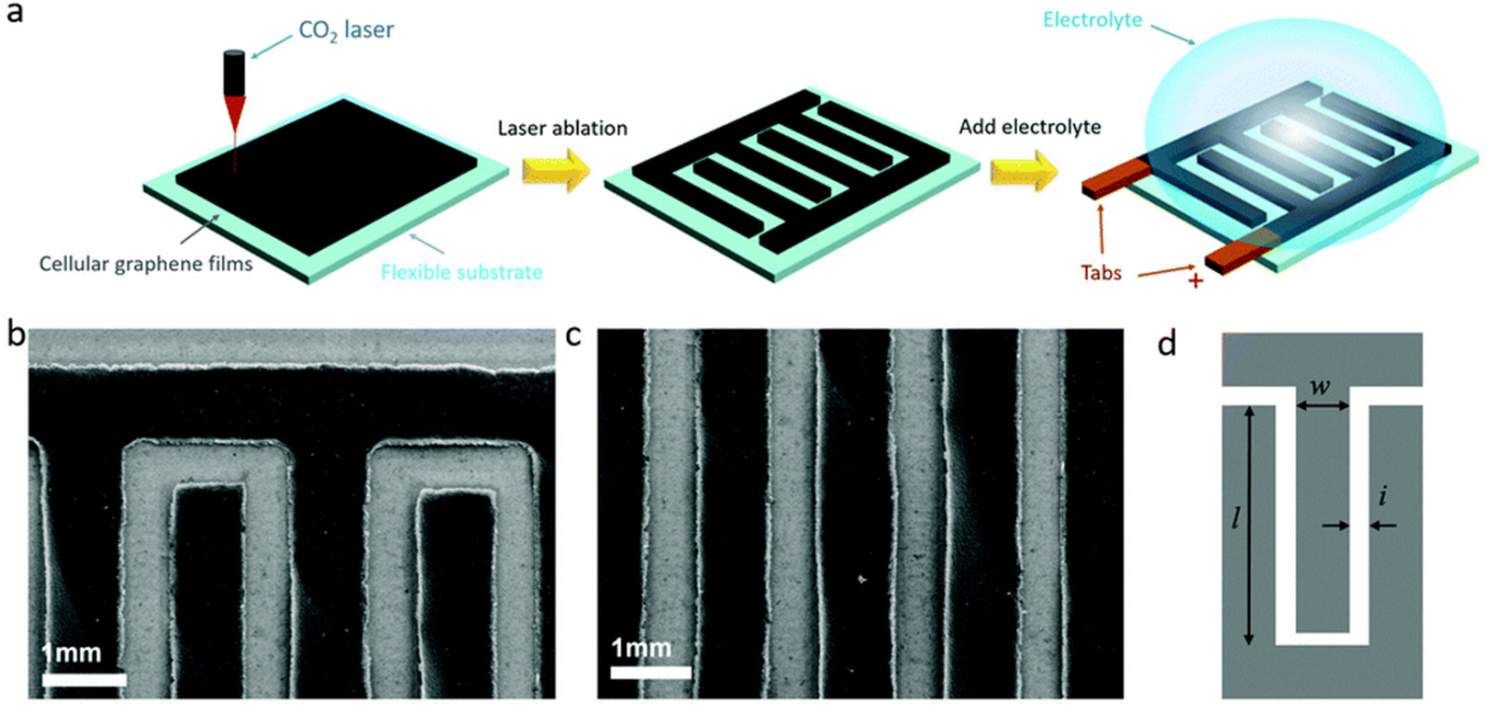

Figure 5. Schematic work flow of the fabrication process of a cellular graphene-based microsupercapacitor through, $\mathrm{CO}_{2}$ laser engraving, to obtain the interdigitated pattern, and then drop casting the gel electrolyte (a); Top-view SEM images of the micro-electrodes $(\mathbf{b}, \mathbf{c})$ and a diagram of the designed pattern dimension (d). Figure reprinted with permission from Shao et al. [83]. Copyright 2017 Royal Society of Chemistry.

\subsection{Onion-Like Carbon}

Onion-like carbon, also called carbon nano-onions, has a well-developed structure, low density, and good stability. Thus, they form excellent electrode material for high performance supercapacitors. Fast charge and discharge rates are enabled by the concentric graphitic multiple shells of carbon onions, allowing facile ion accessibility and high electronic conduction [90]. Onion-like carbon can be synthesized by laser-assisted combustion [91], underwater arc-discharge [92], vacuum annealing [93], and flame pyrolysis [94].

Micro-supercapacitors were produced with nanostructured carbon onions of 6-7 nm diameter, forming a layer of several micrometres using an electrophoretic deposition 
method [40]. Onion-like carbon was decorated with platinum nanoparticles to increase the specific capacitance by four times in comparison to undecorated onion-like carbon [95]. In another study, highly graphitized carbon onion was physically grafted with 1-nitropyrene to achieve an increase in the capacity of the electrode by almost two times to $38 \mathrm{mAh} / \mathrm{g}$, and the initial capacity remained very high even after 4000 cycles [96].

\subsection{Carbide-Derived Carbon}

Carbide-derived carbon (CDC) is of interest because of the control of pore size and pore size distribution, achieved by selectively etching metal atoms from carbide powders, such as metal carbides, carbonitrides, or oxycarbides, through a chlorination process at a certain temperature and duration [97-100]. Alternative ways to prepare CDC include calcium carbide inorganic salt reaction method, hydrothermal leaching, and carbide thermal decomposition [101-103]. The pore size of these materials can be adapted to match the electrolyte solvated ion size, resulting in higher capacitance $[63,104,105]$. Moreover, CDC has outstanding chemical durability and good electrical conductivity. The high surface area of at least up to $1800 \mathrm{~m}^{2} / \mathrm{g}$ in combination with a narrow pore size distribution makes CDC suitable for EDLC electrodes with excellent capacitance [106]. The energy density can be enhanced by combining CDC with high specific capacitance materials such as metal oxides, noble metals, and conducting polymers [107].

Polymer-derived ceramic materials, such as spherical and homogeneous polyorganosilesquioxane particles, produced by a MicroJet reactor technique at large scale, were used as precursor materials for CDC through pyrolysis to silicon oxycarbides [108]. The total pore volume and specific surface area of the produced CDC was $1.3-2.1 \mathrm{~cm}^{3} / \mathrm{g}$ and $2014-2114 \mathrm{~m}^{2} / \mathrm{g}$, respectively. The specific capacitance of the material was $116 \mathrm{~F} / \mathrm{g}$ at $5 \mathrm{~mA} / \mathrm{g}$ and $80 \mathrm{~F} / \mathrm{g}$ at $100 \mathrm{~A} / \mathrm{g}$ in $1 \mathrm{M}$ tetraethylammonium tetrafluoroborate $\left(\mathrm{TEA}-\mathrm{BF}_{4}\right)$ in acetonitrile [108]. In another study, the electrochemical behaviour and performance of micrometre-thick TiC-CDC in 1-ethyl-3-methylimidazolium tetrafluoroborate, (EMIM$\mathrm{BF}_{4}$ ) diluted in either acetonitrile or propylene carbonate, was investigated for microsupercapacitor applications and showed typical capacitive signature with $169 \mathrm{~F} / \mathrm{cm}^{3}$, and energy density of $90 \mu \mathrm{Wh} / \mathrm{cm}^{2}$ in $2 \mathrm{M} \mathrm{EMIBF}_{4} /$ acetonitrile [109]. The influence of nitrogen doping on CDC was tested in supercapacitor set-ups with a conventional organic electrolyte, $1 \mathrm{M} \mathrm{TEA}-\mathrm{BF}_{4}$ in acetonitrile, and an ionic liquid, EMIM-BF 4 . The results showed that the 1 to 7 mass\% nitrogen content did not significantly influence the energy storage capacity, but it had a stronger impact on the rate handling ability [110]. Composites of CDC with titanium oxide were produced with hierarchical structure, using a solvothermal method. The specific capacitance of this composite material for supercapacitors was $173 \mathrm{~F} / \mathrm{g}$, and it had an excellent cycle stability [107].

\section{Micro-Supercapacitor Electrolytes}

Electrolytes are electrically conducting materials, generally solutions with cations and anions in a polar solvent, which can act as an ion source, a conducting material for electric charge, and an electrode particle adhesive. Electrolytes should have conductivity and temperature coefficients that serve a good electrochemical stability range of the supercapacitor, they should have a wide voltage range for a good energy density, high ionic concentration to avoid depletion issues, high electrochemical stability, low volatility, low viscosity, low toxicity, and low cost. Electrolytes come in different states, they can be liquid, solid-state, or quasi-solid-state electrolytes. The liquid electrolytes are divided into three groups, namely aqueous, organic, and ionic electrolytes.

\subsection{Aqueous Electrolytes}

Aqueous electrolytes are of interest because of their high conductivity, low cost, intrinsic non-flammable nature, and because they are environment friendly. Such electrolytes can be acids, alkalis, and inorganic salts. They can provide large capacity and high power density. However, the bottleneck with aqueous electrolytes is the low operating voltage 
because of the narrow electrochemical stability window of water, as pure water decomposes above $1.23 \mathrm{~V}$. Recently, a new strategy was proposed to overcome this challenge, namely by the development of supersaturated water-in-salt electrolytes, which can widen the potential window of aqueous solutions to about $3 \mathrm{~V}$ [111]. In this type of electrolytes, the decomposition of water molecules near the cathode or anode is hindered because the content of free water in these super concentrated aqueous solutions is very low [112].

A $1 \mathrm{M} \mathrm{NaCl}$ electrolyte was employed with binder-free reduced graphene oxide foam electrodes for a micro-supercapacitor with a high capacitance of $618 \mathrm{~F} / \mathrm{g}$ at a current density of $3.0 \mathrm{~A} / \mathrm{g}$ [113]. An aqueous $\mathrm{H}_{2} \mathrm{SO}_{4}$ electrolyte was used for a flexible, simple, lightweight, and low-cost micro-supercapacitor, based on graphene printed on paper, which had a volumetric capacitance of $30 \mathrm{mF} / \mathrm{cm}^{3}$ at $6.5 \mathrm{~mA} / \mathrm{cm}^{3}$ [114]. Similarly, aqueous $\mathrm{H}_{2} \mathrm{SO}_{4}$ solution acted as the electrolyte for a micro-supercapacitor with laser-induced graphene patterned on fluorinated polyimides via a laser photothermal method and resulting in a very large specific surface area of $1126 \mathrm{~m}^{2} / \mathrm{g}$, and a very high areal capacitance of $110 \mathrm{mF} / \mathrm{cm}^{2}$, as determined by cyclic voltammetry [115]. The thin film supercapacitor performance of an aqueous electrolyte, $\mathrm{Li}_{2} \mathrm{SO}_{4}$, was improved using a liquid-carbonprecursor nanoimprint lithography method, with liquid sucrose and lignin used as the precursors for nanoporous carbon materials with high specific surface area of more than $1000 \mathrm{~m}^{2} / \mathrm{g}$ [116]. An aqueous $1 \mathrm{M} \mathrm{Na}_{2} \mathrm{SO}_{4}$ electrolyte was used to test a $\mathrm{MnO}_{2} /$ PEDOT:PSSrGO on a carbon fibre substrate for application in fibre-shaped micro-supercapacitors, resulting in a specific capacitance of $2.9 \mathrm{~F} / \mathrm{cm}^{2}$ at a current density of $5 \mathrm{~mA} / \mathrm{cm}^{2}$, with a $95 \%$ capacity retention after 5000 cycles. The energy density was increased, and a cell voltage of $2.8 \mathrm{~V}$ was achieved for such a fibre-shaped micro-supercapacitor with a waterin-salt electrolyte of super-concentrated potassium acetate instead of conventional dilute aqueous electrolyte [117].

\subsection{Organic Electrolytes}

Organic electrolytes have a wider potential stability window (2-3 V) in comparison to aqueous electrolytes (around 1V). They are formed by dissolving organic salts in organic solvents. The main disadvantages of organic electrolytes include their inferior power performance, their toxicity, and flammability, which limit their application for microsupercapacitors [117]. Moreover, they are sensitive to moisture, and as a consequence, supercapacitors based on organic electrolytes require ultra-dry storage conditions and a complex assembly process, which increases the fabrication cost.

A non-aqueous propylene carbonate electrolyte solution with $0.5 \mathrm{M} \mathrm{LiClO}_{4}$ was tested with $2 \mathrm{wt} \%$ of added organic salt for a supercapacitor with electrodeposited polyaniline, resulting in a specific capacitance of $259 \mathrm{~F} / \mathrm{g}$ and an $80 \%$ capacity retention after 1000 cycles [118]. A micro-supercapacitor with a sulfone-based electrolyte, propylene carbonate/sulfolane/ $\mathrm{LiClO}_{4}$ / polymethyl methacrylate, with mixed manganese/vanadium oxide grown onto multi-wall carbon nanotube electrode, had an operating voltage of up to $2 \mathrm{~V}$ and an areal capacitance of $11.8 \mathrm{mF} / \mathrm{cm}^{2}$ [119].

\subsection{Ionic Liquid Electrolytes}

As the electrochemical stability of the interface, meaning the maximum voltage that can be applied before the redox process is activated, is an important factor determining the energy that can be stored and released. Besides the carbon interfacial area, room temperature ionic liquids are of high interest because of their wide potential stability window (more than $5 \mathrm{~V}$ ) and high thermal stability. They have a lower sensitivity to moisture and oxygen in comparison to organic electrolytes. However, their disadvantages involve their lower conductivity, lower power density due to lower ionic diffusion, and their higher viscosity [117].

Ionic liquid, 1-butyl-3-methylimidazolium bis(trifluoromethylsulfonyl)imide ([BMIM][NTf2]), acted as the electrolyte in a planar thin film supercapacitor with cluster-assembled nanostructured carbon, which reached a capacitance of $75 \mathrm{~F} / \mathrm{g}$ [120]. A flexible micro-supercapacitor 
was made with laser-induced graphene from a polyimide substrate and decorated with red mud nanoparticles, as well as a solid-state ionic liquid electrolyte, composed of poly(vinylidene fluoride), 1-ethyl-3-methylimidazolium bis(trifluoromethylsulfonyl)imide, and 1-ethyl-3-methylimidazolium tetrafluoroborate, which achieved an energy of $0.018 \mathrm{mWh} / \mathrm{cm}^{2}$ at a power of $0.66 \mathrm{~mW} / \mathrm{cm}^{2}$ [121].

\subsection{Solid-State-Electrolytes}

Solid-state electrolytes have the advantages of being leak-proof, high performance, light weight, and a simple packaging and fabrication process. Synthesis of solid-state electrolytes should aim for high ionic conductivity, high chemical, electrochemical, and thermal stability, and sufficient mechanical strength. A main drawback of solid-state electrolytes is the limited mobility of ions, which negatively impacts the power density [122]. Therefore, recent research focused on the development of thin solid-state electrolytes with higher ion mobility and more electrochemically active electrodes [123]. For example, proton-conducting polymers have been used, but they have a narrow potential window, and maintaining a high degree of hydration to maintain high performance can be a challenge [122].

Barium titanate films with incorporated protons by RF magnetron sputtering were fabricated to act as a solid-state electrolyte for micro-supercapacitors, which exhibit a large potential window $(3.2 \mathrm{~V})$, wide operational temperature (about $\left.350^{\circ} \mathrm{C}\right)$, and fast charge and discharge cycles (about $3 \mathrm{~s}$ ) [124].

\subsection{Quasi-Solid-State Electrolytes}

Quasi-solid-state gel polymer electrolytes are flexible and elastic, and are a preferred material for wearable electronics [125]. Gel polymer electrolytes consist of polymer, electrolytic salt, and a solvent, which are either mixed together by melting or solution processes, for example, by in-situ polymerization [126], casting [127] or phase inversion methods $[125,128,129]$. Nevertheless, this type of electrolyte still faces some challenges regarding evaporation of the solvent and decrease in conductivity, leading to a poorer performance of the micro-supercapacitor over time [50]. Ionogel is a specific class of (quasi-)solid-state electrolytes (Figure 6), with fair ionic conductivity and excellent stability, and it is synthesized by mixing fumed silica nanopowder with an ionic liquid, such as 1-ethyl-3-methylimidazolium bis(trifluoromethylsulfonyl)imide [130]. 


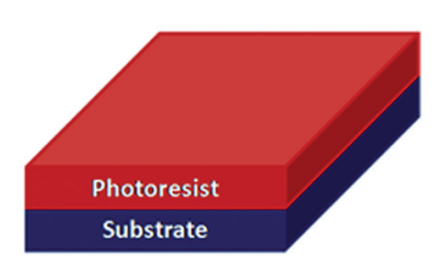

(a)

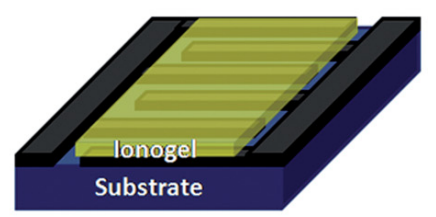

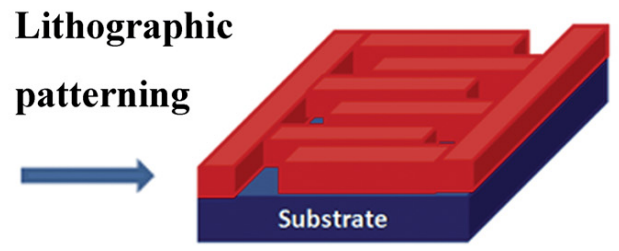
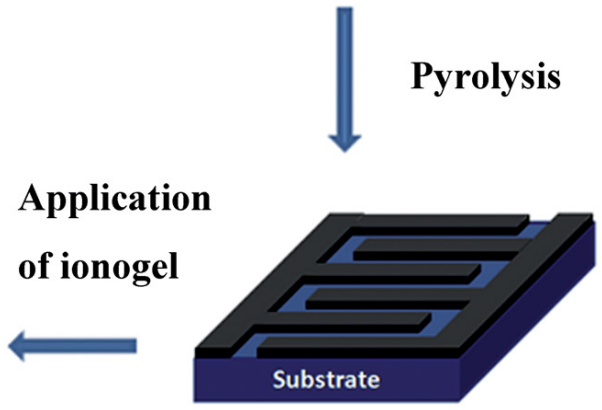
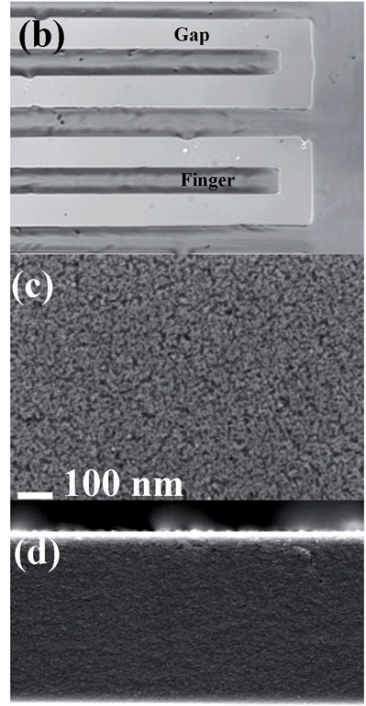

$100 \mathrm{~nm}$

Figure 6. Diagram of a micro-supercapacitor fabrication process with ionogel (a); Optical image of the porous carbon after patterning of the photoresist and pyrolysis (b), SEM top view (c), and cross-sectional view of the pyrolysed area (d). Figure reprinted with permission from Wang et al. [130]. Copyright 2014 the Royal Society of Chemistry.

A quasi-solid-state supercapacitor, produced with polyvinyl alcohol (PVA) $/ \mathrm{H}_{3} \mathrm{PO}_{4}$ electrolyte and 3D porous cellular graphene films, exhibited an energy density of $0.22 \mu \mathrm{Wh} / \mathrm{cm}^{2}$ and a power density of $0.37 \mathrm{~mW} / \mathrm{cm}^{2}$ [83]. Similarly, $\mathrm{PVA} / \mathrm{H}_{3} \mathrm{PO}_{4}$ gel electrolyte was used for a micro-supercapacitor with multi-walled carbon nanotube electrodes, fabricated using mask-free micro-plasma-jet etching at ambient conditions to achieve interdigitated electrode patterns. Such micro-capacitors with 12 interdigitated electrodes had a stack capacitance of $2.0 \mathrm{~F} / \mathrm{cm}^{3}$ at a scan rate of $10 \mathrm{mV} / \mathrm{s}$ [131]. The performance of flexible microsupercapacitors with graphene/PEDOT composite were evaluated with three different gel electrolytes, namely $\mathrm{PVA} / \mathrm{H}_{2} \mathrm{SO}_{4}, \mathrm{PVA} / \mathrm{LiClO}_{4}$, and $\mathrm{PVA} / \mathrm{H}_{3} \mathrm{PO}_{4}$. The results showed that $\mathrm{PVA} / \mathrm{H}_{2} \mathrm{SO}_{4}$ gel electrolyte achieved the highest performance for the graphene/PEDOT micro-supercapacitor with maximum operating potential window of $1.2 \mathrm{~V}$, specific capacitance of $37 \mathrm{mF} / \mathrm{cm}^{2}$, energy density of $6.4 \mathrm{mWh} / \mathrm{cm}^{2}$, and capacitance retention of $89 \%$ after 2500 cycles [132]. In another study, $\mathrm{PVA} / \mathrm{H}_{2} \mathrm{SO}_{4}$ gel electrolyte was used in a micro-supercapacitor with $3 \mathrm{D}$ hierarchical porous lignin-derived carbon $/ \mathrm{WO}_{3}$, prepared by carbonization and a solvothermal process, which had a capacity of $20 \mathrm{mF} / \mathrm{cm}^{2}$ [133].

\section{Fabrication Technologies of Carbon Electrode-Based Micro-Supercapacitors}

The fabrication method of electrodes and micro-supercapacitors can influence the electrochemical performance of the produced devices. One of the underlying factors is the ion and electron transport ability, which is affected by the electrode microstructure. Moreover, the electrode dimension, interspace between the electrodes, and the precision of those are related to the fabrication technique, with consequences for the electrochemical performance [134]. Carbon thin films are constructed either through a bottom-up direct growth approach or via an indirect assembly from small building blocks method [56]. Several methods for thin film electrode fabrication are presented in Figure 7. 

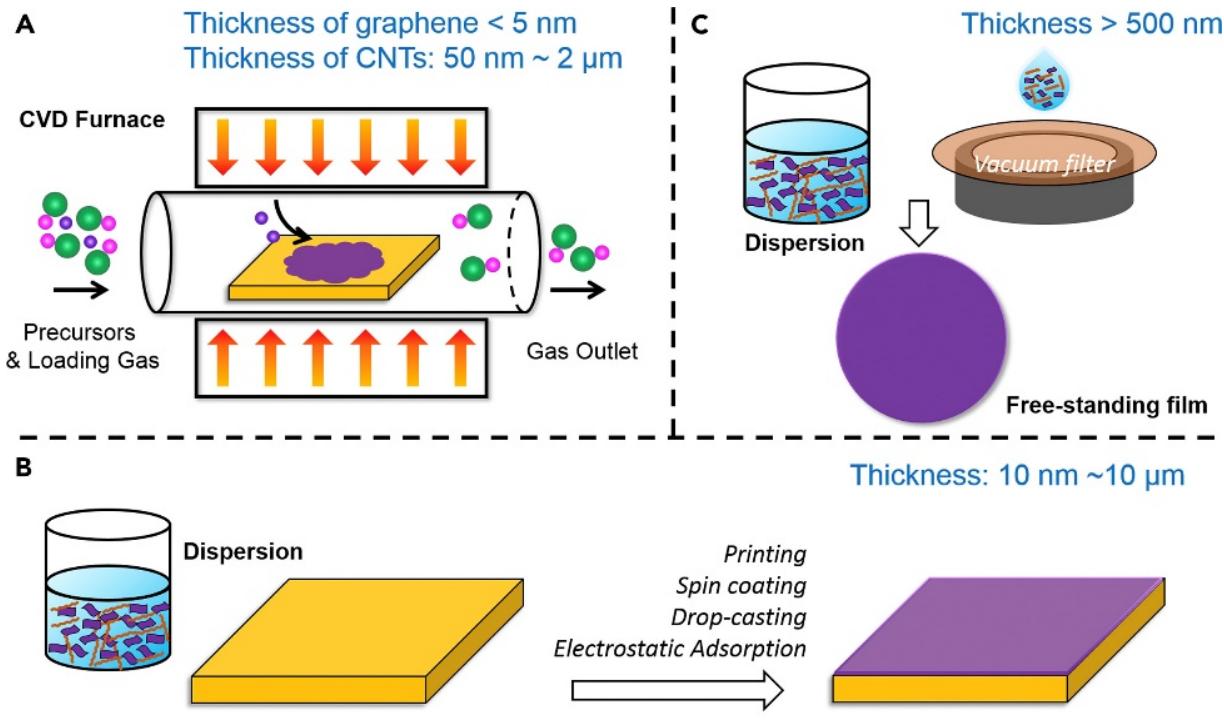

D

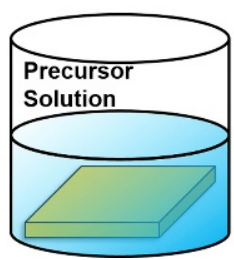

Thickness $<1 \mu \mathrm{m}$
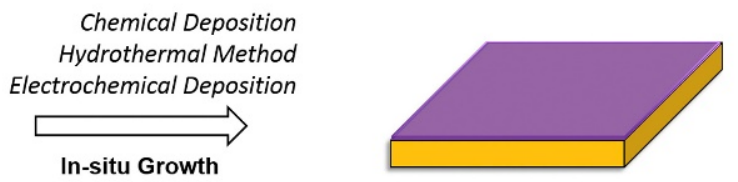

Figure 7. Illustrations of thin film electrode fabrication techniques, with (A) chemical vapour deposition, (B) coating, (C) vacuum filtration, and (D) in situ deposition. Figure reprinted with permission from Yu and Feng [56]. Copyright 2019 Elsevier.

\subsection{Deposition Techniques}

Deposition methods were the first methods applied to fabricate micro-supercapacitors. These methods involve chemical vapour deposition, electrolytic, and electrophoretic deposition.

\subsubsection{Chemical Vapour Deposition}

Chemical vapour deposition is not really suitable for deposition on flexible polymer materials, as they cannot withstand the ultrahigh temperature treatment that comes with this method [50]. Moreover, it is very challenging to achieve selective deposition of carbonbased material on a specific area with chemical vapour deposition. However, some microsupercapacitors were produced using this method [135-139].

Vertically aligned graphitic nanofibers were grown using chemical vapour deposition, and their surface was then coated with ruthenium oxide thin films through an electrochemical deposition process; these coated fibres acted as electrodes in supercapacitors [140]. A solid-state micro-supercapacitor, with thermally reduced graphene oxide, was produced through atmospheric pressure chemical vapour deposition [141].

\subsubsection{Electrophoretic Deposition}

In contrast to chemical vapour deposition, carbon-based electrode materials are commonly deposited by electrolytic and electrophoretic methods. These methods have been documented for activated carbon [142], carbon nanotubes [143], graphene [144], graphene quantum dots [145], and onion-like carbon [146]. They are cost effective, relatively fast, simple, and can be up-scaled using relatively simple fabrication equipment. Moreover, the deposited film thickness can be well controlled using this method. Electrophoretic deposition involves the diffusion, migration, and deposition of charged nanoparticles, nanotubes, or nanosheets onto pre-patterned current collectors by an electric field. 
As an easy and efficient technique, electrophoretic deposition was used to cover silicon nanowires with a graphene coating, which enhanced the performance of microsupercapacitors with such electrodes, resulting in a four times higher capacitance in comparison to uncoated silicon nanowires [147].

\subsubsection{Electrolytic Deposition}

Electrolytic deposition uses redox reactions, in a solution containing precursors, to induce growth of the electrode material under an electric field. The concentration of the electrodeposition solution and the deposition time needs to be tightly controlled in order to avoid the growth of active materials in a lateral direction, which could lead to an electrical short circuit in micro-supercapacitor arrays in series [50].

Porous nano-flake-like $\alpha-\mathrm{Co}(\mathrm{OH})_{2}$ was deposited onto graphene nanosheets by electrodeposition and then functionalized and employed as electrode in hybrid micro-supercapacitors [148]. A two-step electrochemical method was developed to deposit reduced graphene oxide and $\mathrm{MnO}_{2}$ onto Ni fibres, which acted as electrodes in flexible fibre-shaped microsupercapacitors with PVA-LiCl gel solid electrolyte [149]. Synthesis of $\mathrm{Ni}(\mathrm{OH})_{2}$ thin film electrodes involved in situ doping, with carbon nanotubes/reduced graphene oxide by cathodic electrodeposition on titanium mesh, in order to improve the electrochemical performance, as an effect of the doping induced porous structure and conductive network of the thin film [79].

\subsection{Coating Methods}

Coatings methods applied for the fabrication of thin film electrodes with a high surface area and reproducible high structural homogeneity, include spray coating, layer-by-layer assembly, vacuum filtration, spin coating, and dip coating $[150,151]$. With these methods, a coating is achieved by putting a homogeneous dispersion onto a horizontal substrate and letting the solvent evaporate, so a solid film remains, whereby the film thickness can be easily controlled. Thin film electrodes are made from organic, inorganic, or hybrid solutions, and then, the current collector is deposited onto the film by photolithography or spray coating using a shadow mask. Subsequently, quasi-solid-state gel electrolyte is then added onto the film to produce flexible micro-supercapacitors.

\subsubsection{Spray Coating}

Spray coating can be applied using a spray gun or air brush, and it has been used commonly for the fabrication of microelectrodes or film coating [152-157]. The homogeneity and mass loading of active materials depends on the substrate temperature, the distance between the substrate and the spray nozzle, and the deposition time. Another key aspect in this method is that the droplets generated during spraying should not block the nozzle.

The interdigitated architecture of an asymmetric micro-supercapacitor with titanium carbide MXene and reduced graphene oxide electrode materials were fabricated using a custom-made mask and scalable spray coating technique onto a flexible, transparent substrate. Hence, this study did not require photolithography but only simple sequential spray coating of MXene and reduced graphene oxide to produce a 2D micro-supercapacitor [158]. In this process, each sprayed layer was dried completely using a hot air gun, so the coffee ring effect was avoided and uniform coatings were obtained. A custom-made Kapton mask was essential to get the interdigitated pattern electrodes [158]. The spray coating method was also employed to make electrodes of multi-walled carbon nanotubes for high-performance, planar micro-supercapacitors with patterned ionogel electrolyte [159], presented in Figure 8. Ultrasonic spray coating, where droplets are created by ultrasonic vibration, was used to deposit electrode paste with active carbon and one-dimensional silver nanowires onto substrates. A $28 \mathrm{kHz}$ ultrasonic spray nozzle was utilized with a $3 \mathrm{~mL} / \mathrm{min}$ feed rate at 8.7 psi gas-guiding pressure and a distance of $8 \mathrm{~cm}$ between the nozzle and the substrate, with the nozzle moving at $10 \mathrm{~mm} / \mathrm{s}$. Thin film electrodes produced in this manner had a higher specific surface area and pore volume, and ion adsorption and 
desorption were also improved, resulting in better charge storage [160]. In a similar study, ultrasonic spray coating was achieved at the same parameters to make activated carbon thin films doped with silver nanowires, where the effect of the nanowire diameter on the performance of the micro-supercapacitor was investigated [72].

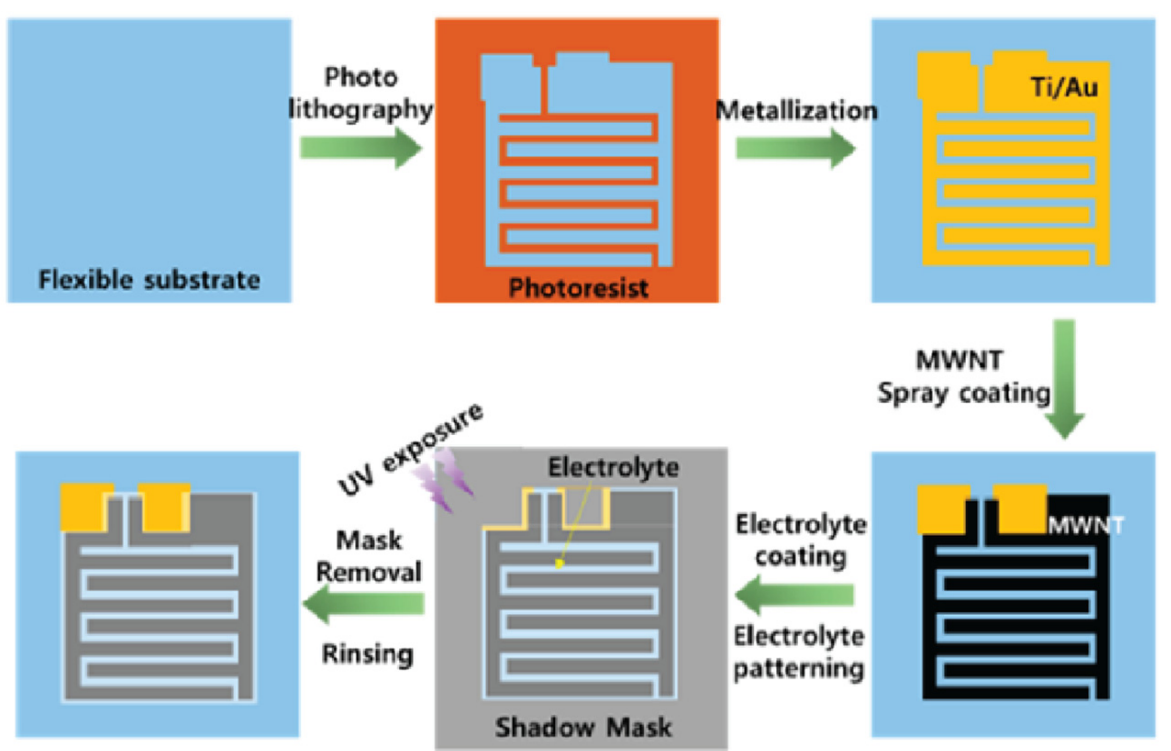

Figure 8. Schematic of the fabrication process of a flexible micro-supercapacitor with patterned solid-state electrolyte on a PET substrate. Figure reprinted with permission from Kim et al. [159]. Copyright 2015 the American Chemical Society.

\subsubsection{Layer-by-Layer Deposition}

Layer-by-layer assembly is a simple, cost-effective method that can be used for large-scale deposition of active materials in films [161]. The micrometre scale film thickness can be easily controlled in this method, whereby layers with opposite charge are alternatively deposited.

Layer-by-layer coating of hybrid $\mathrm{MnO}_{2}$-carbon nanotubes and $\mathrm{MnO}_{2}$-reduced graphene oxide through alternate spray deposition was employed for the fabrication of a costeffective, flexible layered micro-supercapacitor with excellent electrochemical performance [162]. To increase the surface area of electrodes, silver nanowires were wrapped around carbon fibres via an inverted layer-by-layer deposition technique with polydimethylsiloxane (PDMS) for flexible, thin film supercapacitors [163], shown in Figure 9.
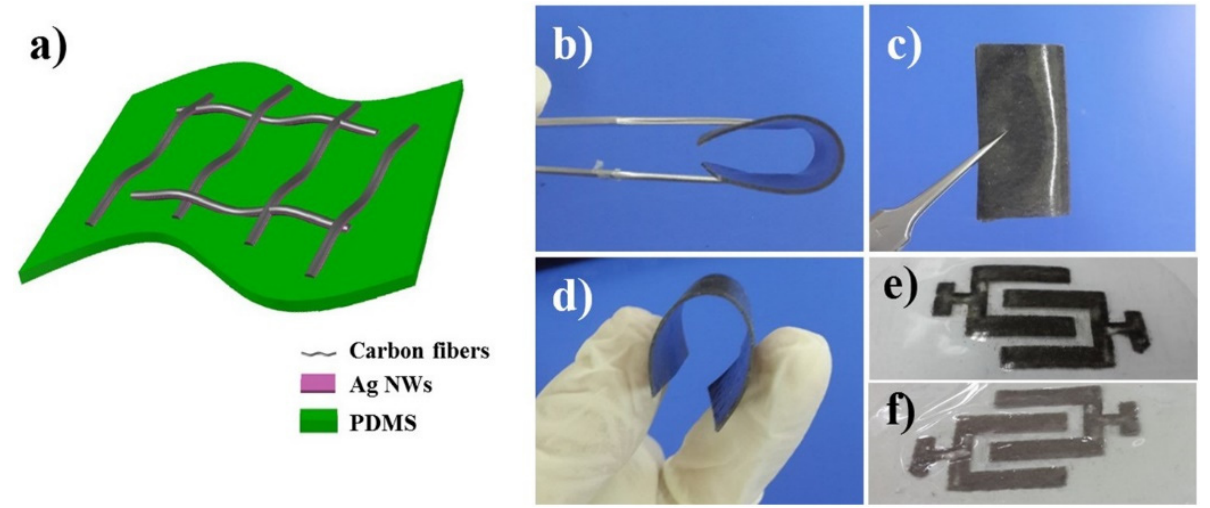

Figure 9. Illustration (a) and photographs of produced flexible PDMS/silver nanowires/carbon fibre film $(\mathbf{b}-\mathbf{d})$, and the patterned electrodes $(\mathbf{e}, \mathbf{f})$. Figure reprinted with permission from Yin et al. [163]. Copyright 2018 Elsevier. 


\subsubsection{Vacuum Filtration}

With vacuum filtration, a solid is separated from liquid, resulting in a stacked dense film, as electrodes with high energy density [164-168]. Several hybrid materials can be formed into uniform films using a range of homogeneous dispersions.

Selective vacuum filtration was used in the fabrication of flexible graphene hydrogel micro-supercapacitors on paper chips [169], illustrated in Figure 10. Single-walled carbon nanotube thin films were also prepared by vacuum filtration, which can then act as electrodes in micro-supercapacitors [78]. A flexible, in-plane asymmetric micro-supercapacitor was fabricated with electrochemical-exfoliated functional graphene oxide and chemicalreduced, functional reduced graphene oxide films, made through mask-assisted vacuum filtration, and solid polyvinyl alcohol/sodium sulphate electrolyte [170]. In a very recent study, a new micro-supercapacitor was developed with MXene/carbon nanotubes composite, acting as the electrode, and fabricated using photolithography followed by vacuum filtration. In this process, the interdigitated structure micro-supercapacitor substrate was first produced on filter paper via photolithography and using a custom-made photomask, and then, silver paste, the MXene-carbon nanotubes composite, and polyvinyl alcohol/sulphuric acid were deposited layer-by-layer on the substrate, as collector, electrode material, and conductive gel electrolyte, respectively, by vacuum filtration [80].

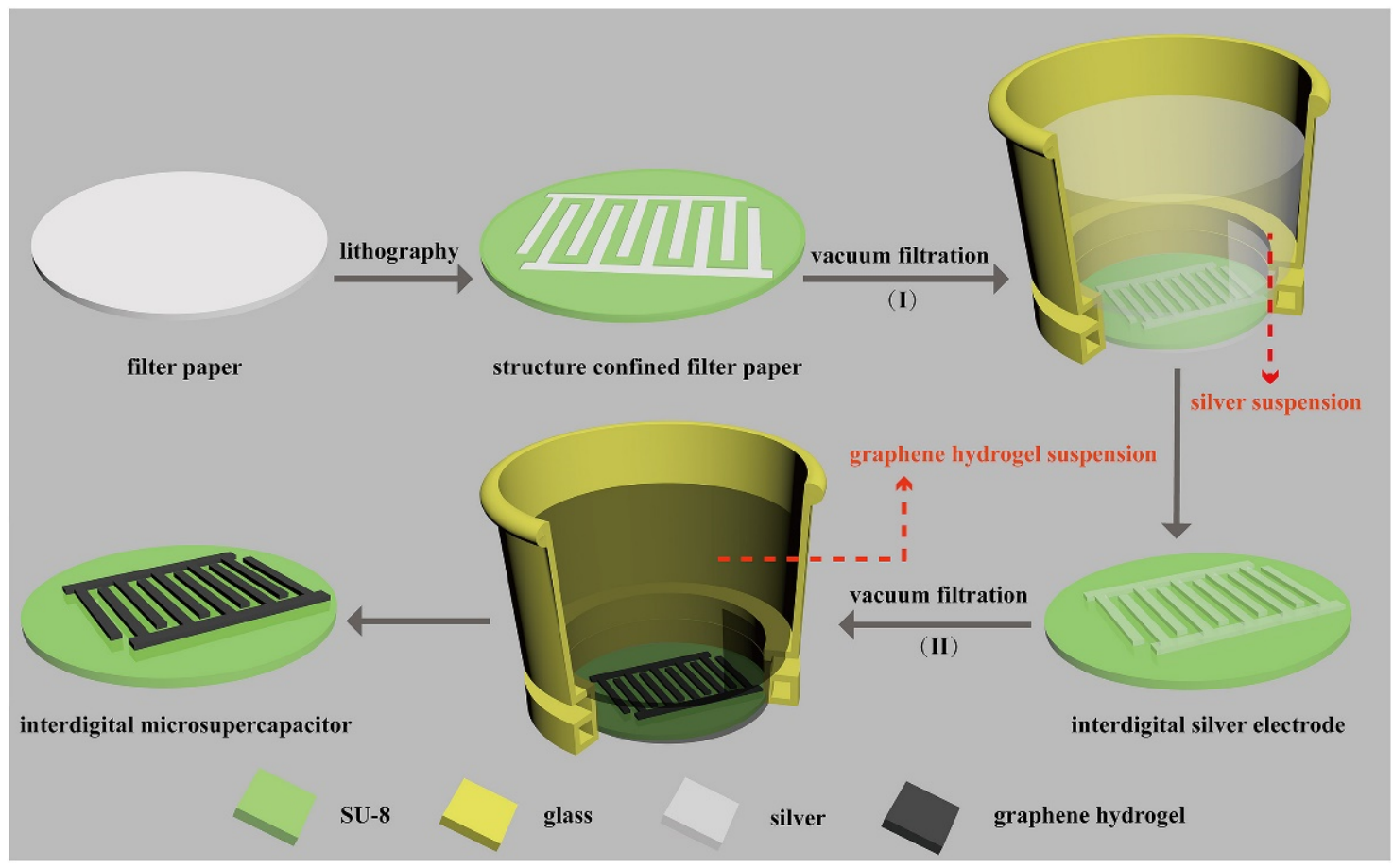

Figure 10. Schematic diagram showing the procedure to fabricate graphene hydrogel microsupercapacitor on paper substrate, with (I) filtration of silver nanoparticles, and (II) filtration of graphene hydrogel suspension. Figure Reprinted with permission from Dong et al. [169]. Copyright 2018 Elsevier.

\subsection{Etching Methods}

There are several etching methods, including laser etching, plasma etching, and gas etching, which are used to engrave patterns at high resolution for micro-supercapacitors. Photolithography with subsequent etching is the most widely used patterning technique for the fabrication of micro-supercapacitors. 


\subsubsection{Laser Etching}

Laser etching is simple, clean, time-saving, and can be up-scaled. The fabrication of microsupercapacitors can be precisely controlled with the laser parameters such as wavelength, scanning speed, pulses per area, pulse duration, pulse frequency, and power [85,171-173].

Laser direct writing has been used for the fabrication of micro-supercapacitors, as the laser can locally reduce graphite oxide to obtain a graphene porous structure, and this method offers more flexibility, in terms of patterning, in comparison to conventional printing or lithographic techniques [174,175]. Moreover, as it does not require contact or masks, this method is simple and cost-effective, and this fabrication method can be used with a pulsed UV laser for micro-writing of reduced graphene oxide electrodes, which are separated by the unreduced portion of the graphite oxide film [176]. Interdigitated patterns were also produced by laser etching on reduced graphene oxide and poly (3,4-ethylenedioxythiophene)/poly(styrenesulfonate) (PEDOT/PSS) composite [177]. The laser direct writing was employed, as well, to fabricate integrated asymmetrical microsupercapacitor arrays (on indium tin oxide-polyethylene terephthalate film) with good flexibility, high areal capacitance, and an energy density of $12.2 \mu \mathrm{Wh} / \mathrm{cm}^{2}$ [178]. Synthesis of $\mathrm{P}$-doped porous graphene micro-capacitors was achieved using laser direct writing on freestanding $\mathrm{H}_{3} \mathrm{PO}_{4}$-incorporated polyimide/polyvinyl alcohol composite membranes [179].

\subsubsection{Plasma Etching}

Plasma etching is also used to fabricate interdigitated microelectrode arrays $[131,180]$. In such process, thin films with electrode materials can be covered with current collector arrays by a combination of photolithography with a mask and sputtering/evaporation. Then, the uncovered parts of the thin films are removed by plasma etching, with the electrode finger arrays remaining. The disadvantages of plasma etching involve the timeconsuming fabrication for micro-supercapacitors and the fact that the method is limited to carbon materials.

An inductively coupled plasma etching technique was employed to fabricate a microsupercapacitor with 3D configuration current collectors. In this study, carbon nanotubes and ruthenium oxide were co-deposited on pre-etched microarrays [181]. Mask-free microplasma-jet etching at ambient conditions is an easy, cost-effective method that is readily scalable. Interdigitated electrode patterns were achieved by localized pulsed plasma jet etching of multi-walled carbon nanotubes by scanning [131], presented in Figure 11.

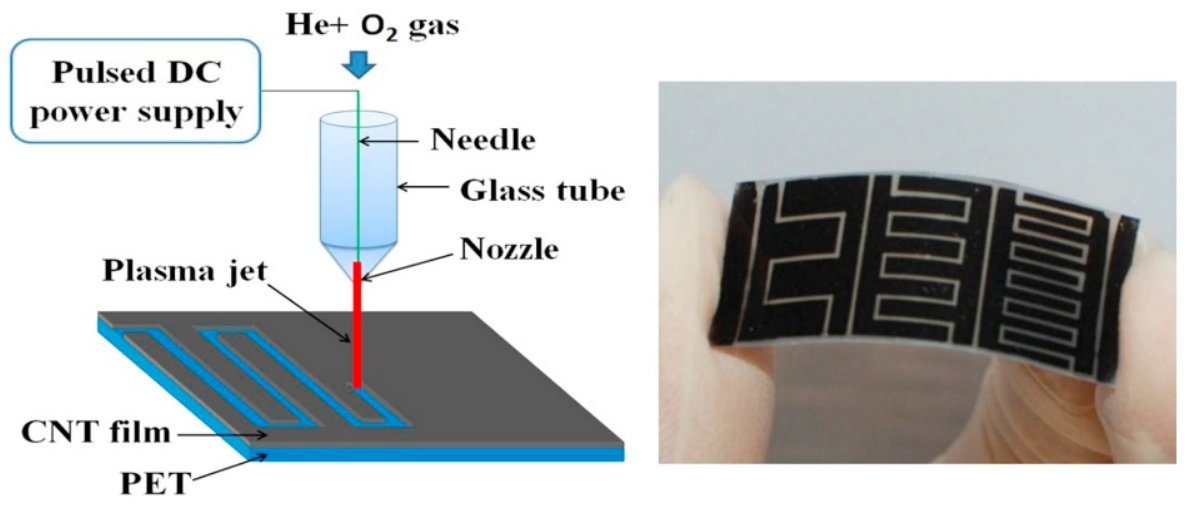

Figure 11. Schematic illustration of the experimental set-up and photograph of patterned carbon nanotube electrodes on PET substrate. Figure reprinted with permission from Liu et al. [131]. Copyright 2017 Elsevier.

\subsection{Printing Technologies}

Printing methods are also used to make interdigitated microelectrode arrays by direct ink writing; these include inkjet printing, screen printing, extrusion printing, gravure printing, and 3D printing [182-185]. These techniques save both time and material, they are cost-effective, and they can be up-scaled. 


\subsubsection{Inkjet Printing}

Commercially available inkjet printers can easily print high resolution patterns with precise control of the width, thickness, distance, and porosity, through the ejection of ink droplets from nozzles onto substrates [186]. Inkjet printing can be used with versatile, environment friendly, and cost-effective precursors by creating small drops on various substrates. This method is a fast process, low cost, and can be up-scaled. To have an efficient inkjet printing process, the ink should have a high solids content and high stability. Moreover, printable ink formulations should have appropriate properties, such as the surface tension and viscosity of the ink.

Inkjet printing was used for the fabrication of a solid-state symmetrical micro-supercapacitor with excellent cycling stability and mechanical flexibility. Therefore, a highly concentrated ink was formulated with two-dimensional $\delta-\mathrm{MnO}_{2}$ nanosheets with a lateral size of $89 \mathrm{~nm}$ and around $1 \mathrm{~nm}$ thickness, and this ink was printed on polyimide film substrates, avoiding the coffee-ring effect [186]. Piezoelectric inkjet printing was developed for one-step printing of liquid carbon precursors with a piezo-driven micro-pipetting system on a 3D printer that enables precise positioning of the ink and thus, high-resolution (down to $200 \mu \mathrm{m}$ with only small spreading) interdigitated micro-supercapacitors with polyvinyl alcohol/hydrogen sulfate hydrogel electrolyte [187], as illustrated in Figure 12. The liquid carbon precursors used in this study were binder-free and did not contain additives, so it converted directly into porous carbon via a pyrolysis step without further processing.

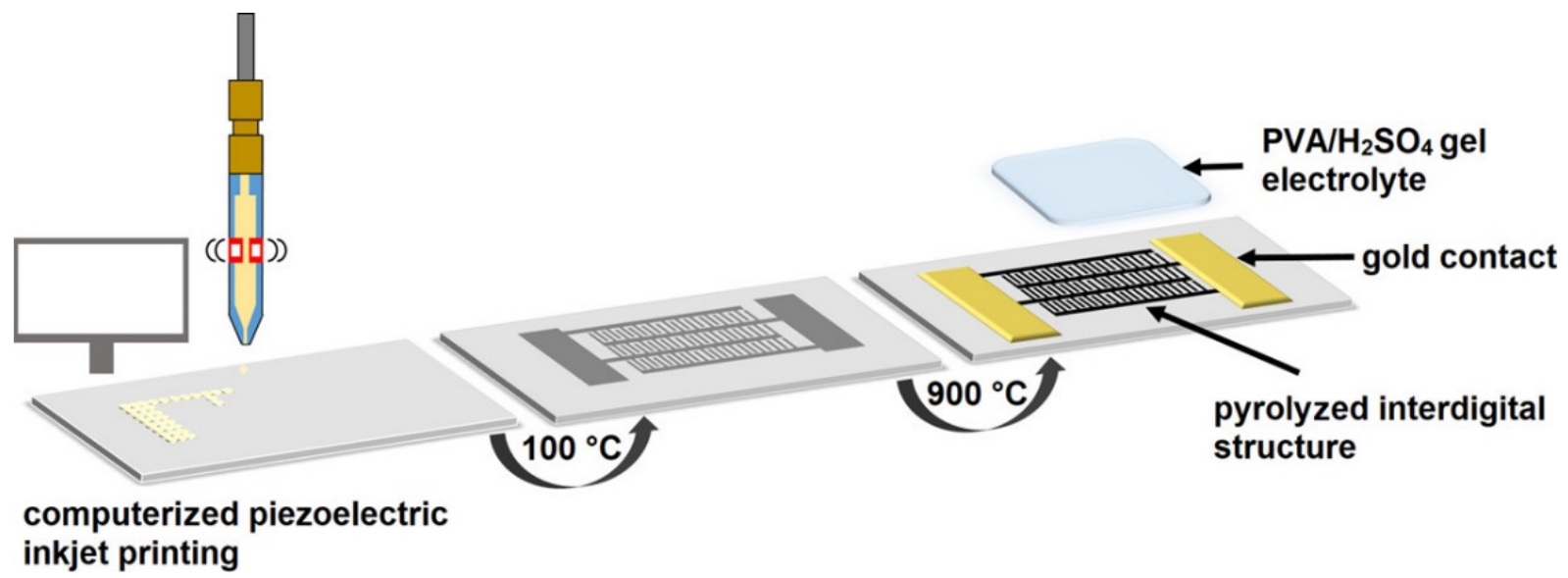

Figure 12. Illustration of the computerized piezoelectric inkjet printing process for micro-supercapacitor fabrication. Figure reprinted with permission from Bräuniger et al. [187]. Copyright 2021 the American Chemical Society.

\subsubsection{Screen Printing}

Screen printing is also a simple, fast, cost-effective technique that can be up-scaled and used for the fabrication of micro-supercapacitors [188-193]. It uses a woven mesh to achieve a targeted pattern; thus, ink is pressed through the mesh openings onto a substrate such as paper, cloth, or plastic.

A micro-supercapacitor, with 3D nanocomposite of cobalt oxide nanoflowers in carbon nanotubes networks (by high-throughput hydrothermal method) as active material, was fabricated using a screen printing technique [194]. Then, the screen-printed active material was covered by dropping polyvinyl alcohol/potassium hydroxide gel electrolyte onto it, and finally, this was stabilized by a PDMS passivation layer. A screen printing method was also applied to make solid-state flexible micro-supercapacitors with 3D boron carbon nitride microspheres (made via hydrothermal and annealing techniques), with an areal capacitance of $41.6 \mathrm{mF} / \mathrm{cm}^{2}$ [195]. A simple fabrication process with screen printing was also employed to make solid-state integrated micro-supercapacitor arrays with porous 
activated biochar (Figure 13), which exhibited an areal capacitance of $116 \mathrm{mF} / \mathrm{cm}^{2}$ and a high areal energy density of $9.3 \mu \mathrm{Wh} / \mathrm{cm}^{2}$ [196].

(a)

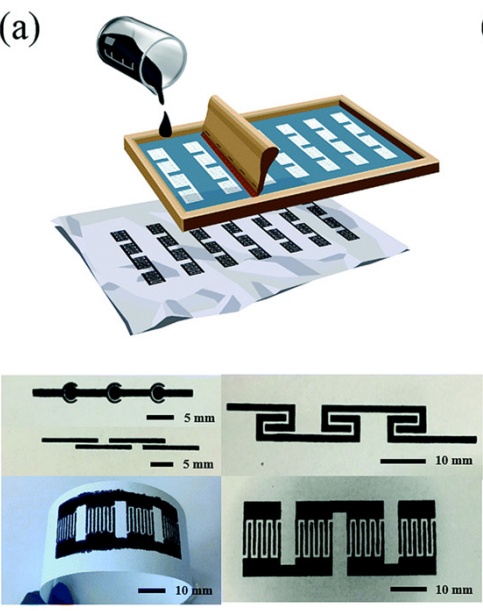

(b)
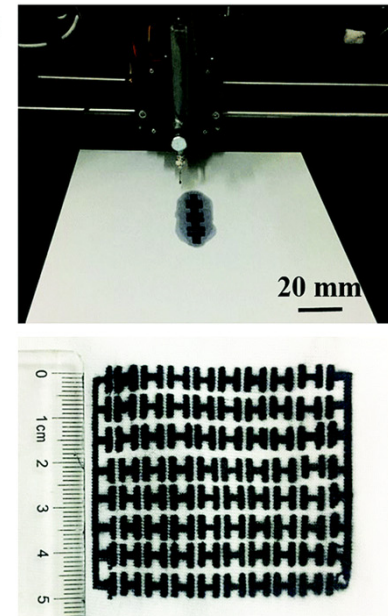

(c)

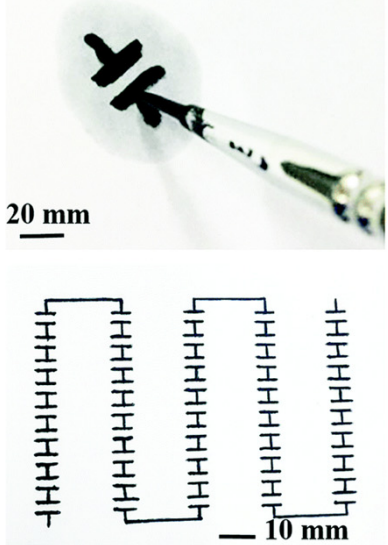

Figure 13. Presentation and photographs of screen printing method (a); programming-controlled writing (b) and painting, using a writing brush (c) to fabricate integrated micro-supercapacitors. Figure reprinted with permission from Liang et al. [196]. Copyright 2021 the Royal Society of Chemistry.

\subsubsection{Gravure Printing}

Gravure printing is also a cost-effective technique for the fabrication of micro-supercapacitors, can have a high output, and is suitable for use with a variety of inks [197,198].

\subsubsection{Extrusion Printing}

Extrusion printing involves the extrusion of an ink through a nozzle; these inks need to have good stability, high viscosity, and they need to be a homogeneous dispersion of active materials. This printing technique can be up-scaled, it is simple and fast, and it is used for the fabrication of micro-supercapacitors $[183,199,200]$.

\subsubsection{D Printing}

Three-dimensional printing is a versatile method for many applications, and it can be used at low cost to make micro-supercapacitors, with several layers to increase thickness. Direct ink writing is the most simple 3D printing technique, which can be employed with many types of materials which have good rheological properties to act as ink [201]. Micro-supercapacitors can also be conveniently fabricated using extrusion-based 3D printing [202-208]. For this, high viscosity inks are required, which also have shear-thinning rheological properties.

Graphene oxide hydrogel with high storage modulus, shear-thinning nature, and fast viscosity recovery acted as a suitable ink for 3D printing through direct ink writing for micro-supercapacitors with interdigitated architecture [209]. To improve ink properties for extrusion-based 3D printing, graphene oxide was subjected to surface modification by treatment with polypyrrole through selective and spontaneous anchoring of polypyrrole without affecting interspaces between the electrodes in micro-supercapacitors [210].

\section{Micro-Supercapacitor Challenges and Future Perspectives}

Several challenges in the field of carbon electrode-based micro-supercapacitors are identified. Research efforts are mainly driven by the never ending quest for high-performance micro-supercapacitors with higher energy density, which can work in a wide voltage range, and have high charge and discharge rates. This implies a search for better materials, electrodes, and electrolytes, as well as design and fabrication methods, which can be upscaled and taken to application. Moreover, a recent trend also focuses on the sustainability 
aspect with synthesis of biomass-derived carbon. The following aspects are expected to be the focus of further research studies.

First, with the increasing demand in wearable electronic devices, there is a high need for flexible micro-supercapacitors. The mechanical properties still need further improvement. Moreover, the substrate preparation procedure needs to be optimized, whereby the electrical response should not change under mechanical loading, so a high performance flexible energy storage device is produced. A better method is needed to measure the mechanical flexibility, and to characterize the physicochemical features of the electrode material and gel electrolyte, during mechanical deformation of flexible micro-supercapacitors.

Second, the most promising, simple, cost-effective micro-supercapacitor fabrication methods that can be up-scaled include laser etching, inkjet printing, and 3D printing. Further development is still needed on a fast, large-scale fabrication technology to pave the way to applications. For the printing techniques, more research is required on engineering the formulations of the printing inks and printing protocols for cost-effective fabrication, enhancing the printing resolution, and making the methods more environment friendly. Micro-machining methods, such as laser etching and screen printing, enable efficient construction of active electrode materials with high conductivity and channels for ion diffusion by introducing pores and heteroatoms. Still, a cost-effective, large-scale production method is required for carbon electrode materials with high capacitance performance. The integration of these flexible micro-supercapacitors as power sources for wearable electronics also needs to be investigated.

Third, the surface area, pore size distribution, surface properties, and electrical conductivity of the electrode material are important for the performance of the microsupercapacitor. Suitable porous carbon should have a high surface area with abundant active sites for ion storage, as well as an appropriate pore structure that may facilitate the storage and transport of ions. Graphene is certainly of interest because of its open structure, which provides both a high active surface area and abundant channels for ion diffusion. Further research involves improving the energy density and power density of micro-supercapacitors by preparing or designing novel carbons with a hierarchical interconnected porous microstructure that matches the desolvated ions. The design, synthesis methods, and stability of high surface area electrode materials, and their accessibility to electrolytes, still need to be further improved. Moreover, surface heteroatoms are important as they enhance the wettability and electrical conductivity, and structural defects generate active sites for ion accumulation. More work is also required on novel models of high performance carbon-based micro-supercapacitors and their charge storage mechanism.

Fourth, the recent research trend on novel carbon electrode materials goes into the field of hybrid micro-supercapacitors to further enhance the performance of microsupercapacitors with higher energy density and wide voltage range. The stability of the pseudocapacitive materials can still be further improved. The potential window can be significantly widened by the use of ionic liquid electrolytes, which are also the subject of recent studies. Water-in-salt electrolytes are also investigated, and their limited ion transport, poor performance at low temperature, and the low cost water-in-salt electrolytes, such as $\mathrm{NaNO}_{3}, \mathrm{NaClO}_{4}$, and $\mathrm{LiCl}$, still need further research.

Fifth, the high interface resistance in solid-state micro-supercapacitors is another challenge to solve in future studies. Long-term integrity between the electrode materials and substrates needs to be developed to reduce internal resistance, which could lead to power failure. More focus is also needed on matching the electrolyte to the electrodes, and optimizing the interface, for example, in gel polymer electrolytes. A stable gel electrolyte needs to be developed with excellent ionic conductivity and thermal stability, as well as higher cycling stability of flexible micro-supercapacitors. The electrolyte is important, not only for the energy and power density of the micro-supercapacitors but also for the stability of the electrode and the device, and a better understanding is needed on charge mechanisms acting at the electrode/electrolyte interface. 
Finally, sustainability is an increasingly important aspect in materials studies. For micro-supercapacitors, recent research involves the synthesis of biomass-derived porous carbon materials. Systematic studies on the correlation of precursor biomass resources, derived carbon materials with micro- and nanostructures, their physical-chemical characteristics, and the electrochemical performance are needed. New synthetic methods need to be developed to produce the carbon materials from biomass and then, use those in electrodes for micro-supercapacitors. Eco-friendly, low-cost manufacturing methods that can be up-scaled are required for mass production. Research studies on biomass-derived carbon materials for micro-supercapacitors also involve heteroatom doping.

\section{Conclusions}

This review has presented an overview of the research progress, mainly of the last five years, on the fabrication of carbon electrode-based micro-supercapacitors. The fast evolution in wearable small electronics, enabled by huge advances in nanotechnology, drives a need for flexible, thin energy storage devices. Supercapacitors have advantages over batteries in terms of their ultrahigh areal power density, long cycle lifetime, and fast charge and discharge time. Supercapacitors are divided into three types based on their charge mechanism: (i) EDLC supercapacitors, (ii) pseudosupercapacitors, and (iii) hybrid supercapacitors. Carbon-based materials are the most common electrode materials for EDLC supercapacitors because of their high thermal and electrochemical stability, low cost, good electrical conductivity, controlled porosity, and appropriate active sites. Microsupercapacitors can occur in two main configurations, namely the stacking configuration and the in-plane interdigitated configuration, and a third type, the fibre-shaped configuration has also been presented.

The performance of supercapacitors is highly impacted by the structural design of the electrode, and to achieve high capacitance, the carbon electrode materials should have a controlled pore structure, large specific surface area, and adequate surface functional groups. Carbon materials commonly used in micro-supercapacitors include activated carbon, carbon nanotubes, graphene, onion-like carbon, and carbide-derived carbon. Recent research on these carbon electrode materials show efforts focused on increasing specific capacitance, making hybrid electrodes, doping of activated carbon, doping graphene with fluorine, laser irradiation of graphene, decoration of onion-like carbon with $\mathrm{Pt}$, making composites of carbon nanotubes with MXene, and composites of graphene with carbidederived carbon.

Also the electrolytes have an influence on the micro-supercapacitor performance. The electrolytes can be divided into five types. Aqueous electrolytes have the advantages of high conductivity, low cost, non-flammable nature, and being environment friendly, but their main challenge is the low operating voltage. A potential solution to the latter challenge is a supersaturated water-in-salt electrolyte. The most common aqueous electrolytes, reported in studies on micro-supercapacitors, include $\mathrm{NaCl}, \mathrm{H}_{2} \mathrm{SO}_{4}, \mathrm{Li}_{2} \mathrm{SO}_{4}$, and $\mathrm{Na}_{2} \mathrm{SO}_{4}$. A second important type of electrolytes concern the organic electrolytes, which have a wider potential stability window. However, they have disadvantages in terms of their toxicity, flammability, sensitivity to moisture, and their inferior power performance. In recent micro-supercapacitor studies, propylene carbonate with sulfolane has been used. Ionic liquids are a third important type of electrolytes, which have a wide potential stability window, high thermal stability, and lower sensitivity to moisture and oxygen in comparison to organic electrolytes. The challenges with ionic liquid electrolytes are mainly the lower conductivity and lower power density. An example of an ionic liquid electrolyte, reported in recent micro-supercapacitor studies, is 1-butyl-3-methylimidazolium bis(trifluoromethylsulfonyl)imide. Next, solid-state electrolytes have the advantage of being leak proof, having a high performance, simple packaging, and a fabrication method. Still, their challenge is the limited ion mobility, which has a negative influence on the power density. Finally, in wearable micro-supercapacitors, which are flexible and elastic, quasi-solid-state electrolytes are used, such as gel polymer electrolytes. The main challenge 
with those electrolytes is the evaporation of the solvent, which can decrease the conductivity. The most common gel electrolytes, reported in recent micro-supercapacitors studies, involve PVA $/ \mathrm{H}_{2} \mathrm{SO}_{4}$ and $\mathrm{PVA} / \mathrm{H}_{3} \mathrm{PO}_{4}$.

The performance of micro-supercapacitors is also impacted by the fabrication technology, which influences the electrode microstructure, such as electrode dimension and interspace, and the precision of those. Four main categories of fabrication technologies have been covered in this review, namely deposition, coating, etching, and printing methods. In terms of deposition methods, chemical vapour deposition is rarely used for micro-supercapacitors since flexible polymers cannot withstand high temperature. Electrophoretic and electrolytic deposition is more commonly used, and they have been reported for graphene coating and doping with carbon nanotubes. Coating with carbon nanotubes, graphene, and active carbon can be achieved through (sequential) spray coating, layer-by-layer coating, and vacuum filtration. Generally, custom-made masks are needed with this technique to generate the interdigitated patterns. Both laser and plasma etching techniques have been employed in the fabrication of micro-supercapacitors, e.g., laser etching to reduce graphite oxide to obtain graphene porous structure and plasma etching for carbon nanotubes. Finally, several printing techniques have been reported, including inkjet, screen, gravure, extrusion, and 3D printing. Inkjet and 3D printing, especially, are receiving increasing attention for the fabrication of micro-supercapacitors. These are simple, fast, cost-effective methods which can be up-scaled.

Funding: This research was funded by KU Leuven Internal Funds Bijzonder Onderzoeksfonds 2020, grant number STG/20/013.

Institutional Review Board Statement: Not applicable.

Informed Consent Statement: Not applicable.

Data Availability Statement: This is a review paper and presents an overview of previously published data.

Conflicts of Interest: The authors declare no conflict of interest.

\section{References}

1. Colombo, A.W.; Karnouskos, S.; Yu, X.H.; Kaynak, O.; Luo, R.C.; Shi, Y.; Leitao, P.; Ribeiro, L.; Haase, J. A 70-Year Industrial Electronics Society Evolution Through Industrial Revolutions: The Rise and Flourishing of Information and Communication Technologies. IEEE Ind. Electron. Mag. 2021, 15, 115-126. [CrossRef]

2. MacManus-Driscoll, J.L. Self-Assembled Heteroepitaxial Oxide Nanocomposite Thin Film Structures: Designing InterfaceInduced Functionality in Electronic Materials. Adv. Funct. Mater. 2010, 20, 2035-2045. [CrossRef]

3. Wang, Z.L.; Wu, W.Z. Nanotechnology-Enabled Energy Harvesting for Self-Powered Micro-/Nanosystems. Angew. Chem. Int. Ed. 2012, 51, 11700-11721. [CrossRef] [PubMed]

4. Kou, L.; Huang, T.Q.; Zheng, B.N.; Han, Y.; Zhao, X.L.; Gopalsamy, K.; Sun, H.Y.; Gao, C. Coaxial wet-spun yarn supercapacitors for high-energy density and safe wearable electronics. Nat. Commun. 2014, 5, 3754. [CrossRef]

5. Chinnappan, A.; Baskar, C.; Baskar, S.; Ratheesh, G.; Ramakrishna, S. An overview of electrospun nanofibers and their application in energy storage, sensors and wearable/flexible electronics. J. Mater. Chem. C 2017, 5, 12657-12673. [CrossRef]

6. Zhang, X.S.; Pei, Z.X.; Wang, C.J.; Yuan, Z.W.; Wei, L.; Pan, Y.Q.; Mahmood, A.; Shao, Q.; Chen, Y. Flexible Zinc-Ion Hybrid Fiber Capacitors with Ultrahigh Energy Density and Long Cycling Life for Wearable Electronics. Small 2019, 15, 1903817. [CrossRef]

7. He, H.X.; Fu, Y.M.; Zhao, T.M.; Gao, X.C.; Xing, L.L.; Zhang, Y.; Xue, X.Y. All-solid-state flexible self-charging power cell basing on piezo-electrolyte for harvesting/storing body-motion energy and powering wearable electronics. Nano Energy 2017, 39, 590-600. [CrossRef]

8. Gu, Y.D.; Zhang, T.; Chen, H.; Wang, F.; Pu, Y.M.; Gao, C.M.; Li, S.B. Mini Review on Flexible and Wearable Electronics for Monitoring Human Health Information. Nanoscale Res. Lett. 2019, 14, 263. [CrossRef]

9. Bai, C.H.; Wang, Z.S.; Yang, S.; Cui, X.J.; Li, X.B.A.; Yin, Y.F.; Zhang, M.; Wang, T.; Sang, S.B.; Zhang, W.D.; et al. Wearable Electronics Based on the Gel Thermogalvanic Electrolyte for Self-Powered Human Health Monitoring. Acs Appl Mater. Inter. 2021, 13, 37306-37312. [CrossRef]

10. Shih, B.; Shah, D.; Li, J.X.; Thuruthel, T.G.; Park, Y.L.; Iida, F.; Bao, Z.A.; Kramer-Bottiglio, R.; Tolley, M.T. Electronic skins and machine learning for intelligent soft robots. Sci. Robot. 2020, 5, aaz9239. [CrossRef]

11. Qiao, Y.C.; Li, X.S.; Jian, J.M.; Wu, Q.; Wei, Y.H.; Shuai, H.; Hirtz, T.; Zhi, Y.; Deng, G.; Wang, Y.F.; et al. Substrate-Free Multilayer Graphene Electronic Skin for Intelligent Diagnosis. ACS Appl. Mater. Inter. 2020, 12, 49945-49956. [CrossRef] 
12. Wang, D.; Chen, X.; Yuan, G.L.; Jia, Y.M.; Wang, Y.P.; Mumtaz, A.; Wang, Y.J.; Liu, J.M. Toward artificial intelligent self-cooling electronic skins: Large electrocaloric effect in all-inorganic flexible thin films at room temperature. J. Mater. 2019, 5, 66-72. [CrossRef]

13. Qiao, Y.C.; Li, X.S.; Wang, J.B.; Ji, S.R.; Hirtz, T.; Tian, H.; Jian, J.M.; Cui, T.R.; Dong, Y.; Xu, X.W.; et al. Intelligent and Multifunctional Graphene Nanomesh Electronic Skin with High Comfort. Small 2021, 119, 2104810. [CrossRef] [PubMed]

14. Donaldson, L. Stretchable and foldable electronic displays. Mater. Today 2013, 16, 416. [CrossRef]

15. Kwon, H.J.; Shim, H.; Kim, S.; Choi, W.; Chun, Y.; Kee, I.; Lee, S. Mechanically and optically reliable folding structure with a hyperelastic material for seamless foldable displays. Appl. Phys. Lett. 2011, 98, 151904. [CrossRef]

16. Han, M.J.; Khang, D.Y. Glass and Plastics Platforms for Foldable Electronics and Displays. Adv. Mater. 2015, 27, 4969. [CrossRef]

17. McRae, M.P.; Simmons, G.; McDevitt, J.T. Challenges and opportunities for translating medical microdevices: Insights from the programmable bio-nano-chip. Bioanalysis 2016, 8, 905-919. [CrossRef]

18. Haga, Y.; Esashi, M. Biomedical microsystems for minimally invasive diagnosis and treatment. Proc. IEEE 2004, 92, 98-114. [CrossRef]

19. Sun, H.; Zhang, Y.; Zhang, J.; Sun, X.M.; Peng, H.S. Energy harvesting and storage in 1D devices. Nat. Rev. Mater. 2017, 2, 17023. [CrossRef]

20. Wang, Y.B.; Chen, C.J.; Xie, H.; Gao, T.T.; Yao, Y.G.; Pastel, G.; Han, X.G.; Li, Y.J.; Zhao, J.P.; Fu, K.; et al. 3D-Printed All-Fiber Li-Ion Battery toward Wearable Energy Storage. Adv. Funct. Mater. 2017, 27, 1703140. [CrossRef]

21. Jung, S.; Hong, S.; Kim, J.; Lee, S.; Hyeon, T.; Lee, M.; Kim, D.H. Wearable Fall Detector using Integrated Sensors and Energy Devices. Sci. Rep. 2015, 5, 17081. [CrossRef]

22. Mackanic, D.G.; Kao, M.; Bao, Z.A. Enabling Deformable and Stretchable Batteries. Adv. Energy Mater. 2020, $10,202001424$. [CrossRef]

23. Wang, Y.H.; Chu, X.; Zhu, Z.H.; Xiong, D.; Zhang, H.T.; Yang, W.Q. Dynamically evolving 2D supramolecular polyaniline nanosheets for long-stability flexible supercapacitors. Chem. Eng. J. 2021, 423, 130203. [CrossRef]

24. Chu, X.; Chen, G.R.; Xiao, X.; Wang, Z.X.; Yang, T.; Xu, Z.; Huang, H.C.; Wang, Y.H.; Yan, C.; Chen, N.J.; et al. Air-Stable Conductive Polymer Ink for Printed Wearable Micro-Supercapacitors. Small 2021, 17, 202100956. [CrossRef]

25. He, H.X.; Zhao, T.M.; Guan, H.Y.; Zhong, T.Y.; Zeng, H.; Xing, L.L.; Zhang, Y.; Xue, X.Y. A water-evaporation-induced self-charging hybrid power unit for application in the Internet of Things. Sci. Bull. 2019, 64, 1409-1417. [CrossRef]

26. Kaempgen, M.; Chan, C.K.; Ma, J.; Cui, Y.; Gruner, G. Printable Thin Film Supercapacitors Using Single-Walled Carbon Nanotubes. Nano Lett. 2009, 9, 1872-1876. [CrossRef]

27. Yang, P.H.; Mai, W.J. Flexible solid-state electrochemical supercapacitors. Nano Energy 2014, 8, 274-290. [CrossRef]

28. Deng, Z.N.; Jiang, H.; Hu, Y.J.; Liu, Y.; Zhang, L.; Liu, H.L.; Li, C.Z. 3D Ordered Macroporous MoS ${ }_{2} @$ C Nanostructure for Flexible Li-Ion Batteries. Adv. Mater. 2017, 29, 201603020. [CrossRef]

29. Ren, J.; Zhang, Y.; Bai, W.Y.; Chen, X.L.; Zhang, Z.T.; Fang, X.; Weng, W.; Wang, Y.G.; Peng, H.S. Elastic and Wearable Wire-Shaped Lithium-Ion Battery with High Electrochemical Performance. Angew. Chem. Int. Ed. 2014, 53, 7864-7869. [CrossRef]

30. Poonam; Sharma, K.; Arora, A.; Tripathi, S.K. Review of supercapacitors: Materials and devices. J. Energy Storage 2019, 21, 801-825. [CrossRef]

31. Afir, A.; Rahman, S.M.H.; Azad, A.T.; Zaini, J.; Islan, M.A.; Azad, A. Advanced materials and technologies for hybrid supercapacitors for energy storage-A review. J. Energy Storage 2019, 25, 100852. [CrossRef]

32. Miller, E.E.; Hua, Y.; Tezel, F.H. Materials for energy storage: Review of electrode materials and methods of increasing capacitance for supercapacitors. J. Energy Storage 2018, 20, 30-40. [CrossRef]

33. Tarascon, J.M.; Armand, M. Issues and challenges facing rechargeable lithium batteries. Nature 2001, 414, 359-367. [CrossRef]

34. Goodenough, J.B.; Park, K.S. The Li-Ion Rechargeable Battery: A Perspective. J. Am. Chem. Soc. 2013, 135, 1167-1176. [CrossRef] [PubMed]

35. Qi, D.P.; Liu, Y.; Liu, Z.Y.; Zhang, L.; Chen, X.D. Design of Architectures and Materials in In-Plane Micro-supercapacitors: Current Status and Future Challenges. Adv. Mater. 2017, 29, 201602802. [CrossRef] [PubMed]

36. Lu, W.; Hartman, R.; Qu, L.T.; Dai, L.M. Nanocomposite Electrodes for High-Performance Supercapacitors. J. Phys. Chem. Lett. 2011, 2, 655-660. [CrossRef]

37. Noori, A.; El-Kady, M.F.; Rahmanifar, M.S.; Kaner, R.B.; Mousavi, M.F. Towards establishing standard performance metrics for batteries, supercapacitors and beyond. Chem. Soc. Rev. 2019, 48, 1272-1341. [CrossRef]

38. Qiu, D.P.; Li, M.; Kang, C.H.; Wei, J.Y.; Wang, F.; Yang, R. Cucurbit 6 uril-Derived Sub-4 nm Pores-Dominated Hierarchical Porous Carbon for Supercapacitors: Operating Voltage Expansion and Pore Size Matching. Small 2020, 16, 202002718. [CrossRef] [PubMed]

39. Sheng, L.Z.; Zhao, Y.Y.; Hou, B.Q.; Xiao, Z.P.; Jiang, L.L.; Fan, Z.J. N-doped layered porous carbon electrodes with high mass loadings for high-performance supercapacitors. New Carbon Mater. 2021, 36, 167-175. [CrossRef]

40. Pech, D.; Brunet, M.; Durou, H.; Huang, P.H.; Mochalin, V.; Gogotsi, Y.; Taberna, P.L.; Simon, P. Ultrahigh-power micrometre-sized supercapacitors based on onion-like carbon. Nat. Nanotechnol. 2010, 5, 651-654. [CrossRef]

41. Largeot, C.; Portet, C.; Chmiola, J.; Taberna, P.L.; Gogotsi, Y.; Simon, P. Relation between the ion size and pore size for an electric double-layer capacitor. J. Am. Chem Soc. 2008, 130, 2730-2731. [CrossRef] [PubMed] 
42. Xing, W.; Qiao, S.Z.; Ding, R.G.; Li, F.; Lu, G.Q.; Yan, Z.F.; Cheng, H.M. Superior electric double layer capacitors using ordered mesoporous carbons. Carbon 2006, 44, 216-224. [CrossRef]

43. Zhang, F.; Liu, T.Y.; Hou, G.H.; Kou, T.Y.; Yue, L.; Guan, R.F.; Li, Y. Hierarchically porous carbon foams for electric double layer capacitors. Nano Res. 2016, 9, 2875-2888. [CrossRef]

44. Senthilkumar, S.T.; Selvan, R.K.; Lee, Y.S.; Melo, J.S. Electric double layer capacitor and its improved specific capacitance using redox additive electrolyte. J. Mater. Chem. A 2013, 1, 1086-1095. [CrossRef]

45. Jian, Z.L.; Raju, V.; Li, Z.F.; Xing, Z.Y.; Hu, Y.S.; Ji, X.L. A High-Power Symmetric Na-Ion Pseudocapacitor. Adv. Funct. Mater. 2015, 25, 5778-5785. [CrossRef]

46. Chen, K.F.; Yang, Y.Y.; Li, K.Y.; Ma, Z.S.; Zhou, Y.C.; Xue, D.F. $\mathrm{CoCl}_{2}$ Designed as Excellent Pseudocapacitor Electrode Materials. Acs Sustain. Chem. Eng. 2014, 2, 440-444. [CrossRef]

47. Wang, H.L.; Casalongue, H.S.; Liang, Y.Y.; Dai, H.J. Ni(OH $)_{2}$ Nanoplates Grown on Graphene as Advanced Electrochemical Pseudocapacitor Materials. J. Am. Chem Soc. 2010, 132, 7472-7477. [CrossRef]

48. Lim, E.; Jo, C.; Kim, M.S.; Kim, M.H.; Chun, J.; Kim, H.; Park, J.; Roh, K.C.; Kang, K.; Yoon, S.; et al. High-Performance Sodium-Ion Hybrid Supercapacitor Based on $\mathrm{Nb}_{2} \mathrm{O}_{5} @$ Carbon Core-Shell Nanoparticles and Reduced Graphene Oxide Nanocomposites. Adv. Funct. Mater. 2016, 26, 3711-3719. [CrossRef]

49. Lv, Q.Y.; Chi, K.; Zhang, Y.; Xiao, F.; Xiao, J.W.; Wang, S.; Loh, K.P. Ultrafast charge/discharge solid-state thin-film supercapacitors via regulating the microstructure of transition-metal-oxide. J. Mater. Chem. A 2017, 5, 2759-2767. [CrossRef]

50. Zhang, P.P.; Wang, F.X.; Yang, S.; Wang, G.; Yu, M.H.; Feng, X.L. Flexible in-plane micro-supercapacitors: Progresses and challenges in fabrication and applications. Energy Storage Mater. 2020, 28, 160-187. [CrossRef]

51. Wang, F.X.; Wu, X.W.; Yuan, X.H.; Liu, Z.C.; Zhang, Y.; Fu, L.J.; Zhu, Y.S.; Zhou, Q.M.; Wu, Y.P.; Huang, W. Latest advances in supercapacitors: From new electrode materials to novel device designs. Chem. Soc. Rev. 2017, 46, 6816-6854. [CrossRef]

52. Liu, C.F.; Liu, Y.C.; Yi, T.Y.; Hu, C.C. Carbon materials for high-voltage supercapacitors. Carbon 2019, 145, 529-548. [CrossRef]

53. Shao, H.; Wu, Y.C.; Lin, Z.F.; Taberna, P.L.; Simon, P. Nanoporous carbon for electrochemical capacitive energy storage. Chem. Soc. Rev. 2020, 49, 3005-3039. [CrossRef] [PubMed]

54. Nomura, K.; Nishihara, H.; Kobayashi, N.; Asada, T.; Kyotani, T. 4.4 V supercapacitors based on super-stable mesoporous carbon sheet made of edge-free graphene walls. Energy Environ. Sci. 2019, 12, 1542-1549. [CrossRef]

55. Ye, M.; Guo, H.W.; Dou, Q.Y.; Guo, H.; Hou, R.L.; Guo, J.H.; Yan, X.B. Optimization of Electrode Potential Ranges for Constructing 4.0 V Carbon-Based Supercapacitors. Chemelectrochem 2020, 7, 201901922. [CrossRef]

56. Yu, M.H.; Feng, X.L. Thin-Film Electrode-Based Supercapacitors. Joule 2019, 3, 338-360. [CrossRef]

57. Kruner, B.; Schreiber, A.; Tolosa, A.; Quade, A.; Badaczewski, F.; Pfaff, T.; Smarsly, B.M.; Presser, V. Nitrogen-containing novolac-derived carbon beads as electrode material for supercapacitors. Carbon 2018, 132, 220-231. [CrossRef]

58. Yan, R.Y.; Antonietti, M.; Oschatz, M. Toward the Experimental Understanding of the Energy Storage Mechanism and Ion Dynamics in Ionic Liquid Based Supercapacitors. Adv. Energy Mater. 2018, 8, 201800026. [CrossRef]

59. An, K.H.; Kim, W.S.; Park, Y.S.; Moon, J.M.; Bae, D.J.; Lim, S.C.; Lee, Y.S.; Lee, Y.H. Electrochemical properties of high-power supercapacitors using single-walled carbon nanotube electrodes. Adv. Funct. Mater. 2001, 11, 387-392. [CrossRef]

60. Wang, Y.; Shi, Z.Q.; Huang, Y.; Ma, Y.F.; Wang, C.Y.; Chen, M.M.; Chen, Y.S. Supercapacitor Devices Based on Graphene Materials. J. Phys. Chem. C 2009, 113, 13103-13107. [CrossRef]

61. Zeiger, M.; Jackel, N.; Weingarth, D.; Presser, V. Vacuum or flowing argon: What is the best synthesis atmosphere for nanodiamondderived carbon onions for supercapacitor electrodes? Carbon 2015, 94, 507-517. [CrossRef]

62. Oschatz, M.; Boukhalfa, S.; Nickel, W.; Hofmann, J.P.; Fischer, C.; Yushin, G.; Kaskel, S. Carbide-derived carbon aerogels with tunable pore structure as versatile electrode material in high power supercapacitors. Carbon 2017, 113, 283-291. [CrossRef]

63. Chmiola, J.; Yushin, G.; Gogotsi, Y.; Portet, C.; Simon, P.; Taberna, P.L. Anomalous increase in carbon capacitance at pore sizes less than 1 nanometer. Science 2006, 313, 1760-1763. [CrossRef] [PubMed]

64. Lee, J.; Kruner, B.; Tolosa, A.; Sathyamoorthi, S.; Kim, D.; Choudhury, S.; Seo, K.H.; Presser, V. Tin/vanadium redox electrolyte for battery-like energy storage capacity combined with supercapacitor-like power handling. Energy Environ. Sci. 2016, 9, 3392-3398. [CrossRef]

65. Fleischmann, S.; Zeiger, M.; Jackel, N.; Kruner, B.; Lemkova, V.; Widmaier, M.; Presser, V. Tuning pseudocapacitive and battery-like lithium intercalation in vanadium dioxide/carbon onion hybrids for asymmetric supercapacitor anodes. J. Mater. Chem. A 2017, 5, 13039-13051. [CrossRef]

66. Ewert, J.K.; Weingarth, D.; Denner, C.; Friedrich, M.; Zeiger, M.; Schreiber, A.; Jackel, N.; Presser, V.; Kempe, R. Enhanced capacitance of nitrogen-doped hierarchically porous carbide-derived carbon in matched ionic liquids. J. Mater. Chem. A 2015, 3 , 18906-18912. [CrossRef]

67. Im, J.S.; Kang, S.C.; Lee, S.H.; Lee, Y.S. Improved gas sensing of electrospun carbon fibers based on pore structure, conductivity and surface modification. Carbon 2010, 48, 2573-2581. [CrossRef]

68. Leitner, K.; Lerf, A.; Winter, M.; Besenhard, J.O.; Villar-Rodil, S.; Suarez-Garcia, F.; Martinez-Alonso, A.; Tascon, J.M.D. Nomexderived activated carbon fibers as electrode materials in carbon based supercapacitors. J. Power Sources 2006, 153, $419-423$. [CrossRef] 
69. Wang, Q.; Plylahan, N.; Shelke, M.V.; Devarapalli, R.R.; Li, M.S.; Subramanian, P.; Djenizian, T.; Boukherroub, R.; Szunerits, S. Nanodiamond particles/reduced graphene oxide composites as efficient supercapacitor electrodes. Carbon 2014, 68, 175-184. [CrossRef]

70. Kang, Y.J.; Chung, H.; Kim, M.S.; Kim, W. Enhancement of CNT/PET film adhesion by nano-scale modification for flexible all-solid-state supercapacitors. Appl. Surf. Sci. 2015, 355, 160-165. [CrossRef]

71. Fan, L.Q.; Liu, G.J.; Wu, J.H.; Liu, L.; Lin, J.M.; Wei, Y.L. Asymmetric supercapacitor based on graphene oxide/polypyrrole composite and activated carbon electrodes. Electrochim. Acta 2014, 137, 26-33. [CrossRef]

72. Lin, J.Y.; Huang, J.J.; Hsueh, Y.L.; Zhang, Y.X. Diameter effect of silver nanowire doped in activated carbon as thin film electrode for high performance supercapacitor. Appl. Surf. Sci. 2019, 477, 257-263. [CrossRef]

73. Zhang, Y.X.; Wuu, D.S.; Huang, J.J. Preparation of AgNWs@NiO- $\mathrm{Co}_{3} \mathrm{O}_{4}$ dopant material for an activated carbon thin-film electrode of pseudocapacitors. J. Mater. Sci. 2021, 56, 15229-15240. [CrossRef]

74. Xu, J.; Ruan, C.H.; Li, P.X.; Xie, Y.B. Excessive nitrogen doping of tin dioxide nanorod array grown on activated carbon fibers substrate for wire-shaped microsupercapacitor. Chem. Eng. J. 2019, 378, 122064. [CrossRef]

75. Huang, J.J.; Zhang, Y.X.; Zhang, J.X. Characterization of $\mathrm{MnO}_{2}$ and AgNWs Co-Doped into an Activated Carbon Thin Film Electrode for Supercapacitors. J. Electron. Mater. 2021, 50, 6535-6544. [CrossRef]

76. Tang, Q.; Chen, X.Y.; Zhou, D.L.; Liu, C. Biomass-derived hierarchical porous carbon/silicon carbide composite for electrochemical supercapacitor. Colloids Surf. A-Physicochem. Eng. Asp. 2021, 620, 126567. [CrossRef]

77. Laszczyk, K.U.; Futaba, D.N.; Kobashi, K.; Hata, K.; Yamada, T.; Sekiguchi, A. The limitation of electrode shape on the operational speed of a carbon nanotube based micro-supercapacitor. Sustain. Energy Fuels 2017, 1, 1282-1286. [CrossRef]

78. Durukan, M.B.; Yuksel, R.; Unalan, H.E. Cobalt Oxide Nanoflakes on Single Walled Carbon Nanotube Thin Films for Supercapacitor Electrodes. Electrochim. Acta 2016, 222, 1475-1482. [CrossRef]

79. Han, C.; Cao, W.Y.; Si, H.Z.; Wu, Y.; Liu, K.Y.; Liu, H.T.; Sang, S.B.; Wu, Q.M. One-step electrodeposition synthesis of high performance carbon nanotubes/graphene-doped $\mathrm{Ni}(\mathrm{OH})_{2}$ thin film electrode for high-performance supercapacitor. Electrochim. Acta 2019, 322, 134747. [CrossRef]

80. Wang, R.C.; Luo, S.H.; Xiao, C.; Chen, Z.Y.; Li, H.S.; Asif, M.; Chan, V.; Liao, K.; Sun, Y.M. MXene-carbon nanotubes layer-by-layer assembly based on-chip micro-supercapacitor with improved capacitive performance. Electrochim. Acta 2021, 386, 138420. [CrossRef]

81. Yang, H.J.; Lee, J.W.; Seo, S.H.; Jeong, B.; Lee, B.H.; Do, W.J.; Kim, J.H.; Cho, J.Y.; Jo, A.; Jeong, H.J.; et al. Fully stretchable self-charging power unit with micro-supercapacitor and triboelectric nanogenerator based on oxidized single-walled carbon nanotube/polymer electrodes. Nano Energy 2021, 86, 106083. [CrossRef]

82. Dousti, B.; Choi, Y.I.; Cogan, S.F.; Lee, G.S. A High Energy Density 2D Microsupercapacitor Based on an Interconnected Network of a Horizontally Aligned Carbon Nanotube Sheet. Acs Appl. Mater. Inter. 2020, 12, 50011-50023. [CrossRef] [PubMed]

83. Shao, Y.L.; Li, J.M.; Li, Y.G.; Wang, H.Z.; Zhang, Q.H.; Kaner, R.B. Flexible quasi-solid-state planar micro-supercapacitor based on cellular graphene films. Mater. Horiz. 2017, 4, 1145-1150. [CrossRef]

84. He, D.X.; Marsden, A.J.; Li, Z.L.; Zhao, R.; Xue, W.D.; Bissett, M.A. A single step strategy to fabricate graphene fibres via electrochemical exfoliation for micro-supercapacitor applications. Electrochim. Acta 2019, 299, 645-653. [CrossRef]

85. Zhang, L.; DeArmond, D.; Alvarez, N.T.; Malik, R.; Oslin, N.; McConnell, C.; Adusei, P.K.; Hsieh, Y.Y.; Shanov, V. Flexible Micro-Supercapacitor Based on Graphene with 3D Structure. Small 2017, 13, 201603114. [CrossRef] [PubMed]

86. Kamboj, N.; Purkait, T.; Das, M.; Sarkar, S.; Hazra, K.S.; Dey, R.S. Ultralong cycle life and outstanding capacitive performance of a $10.8 \mathrm{~V}$ metal free micro-supercapacitor with highly conducting and robust laser-irradiated graphene for an integrated storage device. Energy Environ. Sci. 2019, 12, 01458. [CrossRef]

87. Cho, S.; Kim, J.; Jo, Y.; Ahmed, A.T.A.; Chavan, H.S.; Woo, H.; Inamdar, A.I.; Gunjakar, J.L.; Pawar, S.M.; Park, Y.; et al. Bendable $\mathrm{RuO} 2$ /graphene thin film for fully flexible supercapacitor electrodes with superior stability. J. Alloy. Compd. 2017, 725, 108-114. [CrossRef]

88. Yan, P.T.; Yan, L.; Zhao, S.M.; Zuo, Z.; Wang, X.X.; Wang, C.L.; Hou, M.L. Fluorine-Doped Graphene/Nanosized Carbide-Derived Carbon Composites for High-Performance Supercapacitor. Nano 2019, 14, 1950099. [CrossRef]

89. Qin, J.Q.; Gao, J.M.; Shi, X.Y.; Chang, J.Y.; Dong, Y.F.; Zheng, S.H.; Wang, X.; Feng, L.; Wu, Z.S. Hierarchical Ordered DualMesoporous Polypyrrole/Graphene Nanosheets as Bi-Functional Active Materials for High-Performance Planar Integrated System of Micro-Supercapacitor and Gas Sensor. Adv. Funct. Mater. 2020, 30, 1909756. [CrossRef]

90. Mohapatra, D.; Badrayyana, S.; Parida, S. A Facile Method for High Yield Synthesis of Carbon Nano Onions for Designing Binder-Free Flexible Supercapacitor. In Proceedings of the 61st DAE-Solid State Physics Symposium, Bhubaneswar, India, 26-30 December 2016.

91. Gao, Y.; Zhou, Y.S.; Qian, M.; He, X.N.; Redepenning, J.; Goodman, P.; Li, H.M.; Jiang, L.; Lu, Y.F. Chemical activation of carbon nano-onions for high-rate supercapacitor electrodes. Carbon 2013, 51, 52-58. [CrossRef]

92. Borgohain, R.; Yang, J.C.; Selegue, J.P.; Kim, D.Y. Controlled synthesis, efficient purification, and electrochemical characterization of arc-discharge carbon nano-onions. Carbon 2014, 66, 272-284. [CrossRef]

93. Portet, C.; Yushin, G.; Gogotsi, Y. Electrochemical performance of carbon onions, nanodiamonds, carbon black and multiwalled nanotubes in electrical double layer capacitors. Carbon 2007, 45, 2511-2518. [CrossRef] 
94. Ramya, A.V.; Thomas, R.; Balachandran, M. Mesoporous onion-like carbon nanostructures from natural oil for high-performance supercapacitor and electrochemical sensing applications: Insights into the post-synthesis sonochemical treatment on the electrochemical performance. Ultrason. Sonochem. 2021, 79, 105767. [CrossRef]

95. Wang, C.D.; Wu, C.Q.; Chen, S.M.; He, Q.; Liu, D.B.; Zheng, X.S.; Haleem, Y.A.; Song, L. In situ synthesis of noble metal nanoparticles on onion-like carbon with enhanced electrochemical and supercapacitor performance. Rsc. Adv. 2017, 7, 4667-4670. [CrossRef]

96. Anothumakkool, B.; Taberna, P.L.; Daffos, B.; Simon, P.; Sayed-Ahmad-Baraza, Y.M.; Ewels, C.; Brousse, T.; Gaubicher, J. Improved electro-grafting of nitropyrene onto onion-like carbon via in situ electrochemical reduction and polymerization: Tailoring redox energy density of the supercapacitor positive electrode. J. Mater. Chem. A 2017, 5, 1488-1494. [CrossRef]

97. Gogotsi, Y.; Nikitin, A.; Ye, H.H.; Zhou, W.; Fischer, J.E.; Yi, B.; Foley, H.C.; Barsoum, M.W. Nanoporous carbide-derived carbon with tunable pore size. Nat. Mater. 2003, 2, 591-594. [CrossRef] [PubMed]

98. Dash, R.; Chmiola, J.; Yushin, G.; Gogotsi, Y.; Laudisio, G.; Singer, J.; Fischer, J.; Kucheyev, S. Titanium carbide derived nanoporous carbon for energy-related applications. Carbon 2006, 44, 2489-2497. [CrossRef]

99. Perez, C.R.; Yeon, S.H.; Segalini, J.; Presser, V.; Taberna, P.L.; Simon, P.; Gogotsi, Y. Structure and Electrochemical Performance of Carbide-Derived Carbon Nanopowders. Adv. Funct. Mater. 2013, 23, 1081-1089. [CrossRef]

100. Chmiola, J.; Largeot, C.; Taberna, P.L.; Simon, P.; Gogotsi, Y. Monolithic Carbide-Derived Carbon Films for Micro-Supercapacitors. Science 2010, 328, 480-483. [CrossRef] [PubMed]

101. Kraft, T.; Nickel, K.G.; Gogotsi, Y.G. Hydrothermal degradation of chemical vapour deposited SiC fibres. J. Mater. Sci. 1998, 33, 4357-4364. [CrossRef]

102. Kraft, T.; Nickel, K.G. Carbon formed by hydrothermal treatment of alpha-SiC crystals. J. Mater. Chem. 2000, 10, 671-680. [CrossRef]

103. Welz, S.; McNallan, M.J.; Gogotsi, Y. Carbon structures in silicon carbide derived carbon. J. Mater. Process. Technol. 2006, 179, 11-22. [CrossRef]

104. Chmiola, J.; Yushin, G.; Dash, R.; Gogotsi, Y. Effect of pore size and surface area of carbide derived carbons on specific capacitance. J. Power Sources 2006, 158, 765-772. [CrossRef]

105. Beguin, F.; Presser, V.; Balducci, A.; Frackowiak, E. Carbons and Electrolytes for Advanced Supercapacitors. Adv. Mater. 2014, 26, 2219-2251. [CrossRef] [PubMed]

106. Tee, E.; Tallo, I.; Kurig, H.; Thomberg, T.; Janes, A.; Lust, E. Huge enhancement of energy storage capacity and power density of supercapacitors based on the carbon dioxide activated microporous SiC-CDC. Electrochim. Acta 2015, 161, 364-370. [CrossRef]

107. Zhong, W.Q.; Sun, H.Y.; Pan, J.M.; Zhang, Y.H.; Yan, X.H.; Guan, Y.; Shen, W.; Cheng, X.N. Hierarchical porous TiO 2 / carbidederived carbon for asymmetric supercapacitor with enhanced electrochemical performance. Mater. Sci. Semicond. Process. 2021, 127, 105715. [CrossRef]

108. Kruner, B.; Odenwald, C.; Tolosa, A.; Schreiber, A.; Aslan, M.; Kickelbick, G.; Presser, V. Carbide-derived carbon beads with tunable nanopores from continuously produced polysilsesquioxanes for supercapacitor electrodes. Sustain. Energy Fuels 2017, 1, 1588-1600. [CrossRef]

109. Brousse, K.; Huang, P.; Pinaud, S.; Respaud, M.; Daffos, B.; Chaudret, B.; Lethien, C.; Taberna, P.L.; Simon, P. Electrochemical behavior of high performance on-chip porous carbon films for micro-supercapacitors applications in organic electrolytes. J. Power Sources 2016, 328, 520-526. [CrossRef]

110. Kruner, B.; Odenwald, C.; Quade, A.; Kickelbick, G.; Presser, V. Influence of Nitrogen-Doping for Carbide-Derived Carbons on the Supercapacitor Performance in an Organic Electrolyte and an Ionic Liquid. Batter. Supercaps 2018, 1, 135-148. [CrossRef]

111. Bahdanchyk, M.; Hashempour, M.; Vicenzo, A. Evaluation of the operating potential window of electrochemical capacitors. Electrochim Acta 2020, 332, 135503. [CrossRef]

112. Guo, J.H.; Ma, Y.L.; Zhao, K.; Wang, Y.; Yang, B.P.; Cui, J.F.; Yan, X.B. High-Performance and Ultra-Stable Aqueous Supercapacitors Based on a Green and Low-Cost Water-In-Salt Electrolyte. ChemElectroChem 2019, 6, 5433-5438. [CrossRef]

113. Madani, S.; Falamaki, C.; Alimadadi, H.; Aboutalebi, S.H. Binder-free reduced graphene oxide 3D structures based on ultra large graphene oxide sheets: High performance green micro-supercapacitor using NaCl electrolyte. J. Energy Storage 2019, 21, 310-320. [CrossRef]

114. Nagar, B.; Dubal, D.P.; Pires, L.; Merkoci, A.; Gomez-Romero, P. Design and Fabrication of Printed Paper-Based Hybrid Micro-Supercapacitor by using Graphene and Redox-Active Electrolyte. ChemSusChem 2018, 11, 1849-1856. [CrossRef]

115. Kim, M.; Gu, M.G.; Jeong, H.; Song, E.; Jeon, J.W.; Huh, K.M.; Kang, P.; Kim, S.K.; Kim, B.G. Laser Scribing of Fluorinated Polyimide Films to Generate Microporous Structures for High-Performance Micro-supercapacitor Electrodes. Acs Appl. Energy Mater. 2021, 4, 208-214. [CrossRef]

116. Lochmann, S.; Grothe, J.; Eckhardt, K.; Leistenschneider, D.; Borchardt, L.; Kaskel, S. Nanoimprint lithography of nanoporous carbon materials for micro-supercapacitor architectures. Nanoscale 2018, 10, 10109-10115. [CrossRef]

117. Naderi, L.; Shahrokhian, S.; Soavi, F. Fabrication of a $2.8 \mathrm{~V}$ high-performance aqueous flexible fiber-shaped asymmetric micro-supercapacitor based on MnO2/PEDOT:PSS-reduced graphene oxide nanocomposite grown on carbon fiber electrode. J. Mater. Chem. A 2020, 8, 19588-19602. [CrossRef]

118. Jo, Y.; Cho, W.J.; Inamdar, A.I.; Kim, B.C.; Kim, J.M.; Kim, H.S.; Im, H.S.; Yu, K.H.; Kim, D.Y. Electrochemical Supercapacitor Properties of Polyaniline Thin Films in Organic Salt Added Electrolytes. J. Appl. Polym. Sci. 2014, 131, 40306. [CrossRef] 
119. Park, H.; Song, C.; Jin, S.W.; Lee, H.; Keum, K.; Lee, Y.H.; Lee, G.; Jeong, Y.R.; Ha, J.S. High performance flexible microsupercapacitor for powering a vertically integrated skin-attachable strain sensor on a bio-inspired adhesive. Nano Energy 2021, 83, 105837. [CrossRef]

120. Bettini, L.G.; Galluzzi, M.; Podesta, A.; Milani, P.; Piseri, P. Planar thin film supercapacitor based on cluster-assembled nanostructured carbon and ionic liquid electrolyte. Carbon 2013, 59, 212-220. [CrossRef]

121. Bhattacharya, G.; Fishlock, S.J.; Pritam, A.; Roy, S.S.; McLaughlin, J.A. Recycled Red Mud-Decorated Porous 3D Graphene for High-Energy Flexible Micro-Supercapacitor. Adv. Sustain. Syst. 2020, 4, 201900133. [CrossRef]

122. Gao, H.; Lian, K. Proton-conducting polymer electrolytes and their applications in solid supercapacitors: A review. Rsc. Adv. 2014, 4, 33091-33113. [CrossRef]

123. Huang, C.; Zhang, J.; Young, N.P.; Snaith, H.J.; Grant, P.S. Solid-state supercapacitors with rationally designed heterogeneous electrodes fabricated by large area spray processing for wearable energy storage applications. Sci. Rep. 2016, 6, 25684. [CrossRef] [PubMed]

124. Ben Cheikh, Z.; El Kamel, F.; Gallot-Lavallee, O.; Soussou, M.A.; Vizireanu, S.; Achour, A.; Khirouni, K. Hydrogen doped BaTiO3 films as solid-state electrolyte for micro-supercapacitor applications. J. Alloy. Compd. 2017, 721, 276-284. [CrossRef]

125. Cheng, X.L.; Pan, J.; Zhao, Y.; Liao, M.; Peng, H.S. Gel Polymer Electrolytes for Electrochemical Energy Storage. Adv. Energy Mater. 2018, 8, 1702184. [CrossRef]

126. Vijayakumar, V.; Anothumakkool, B.; Torris, A.T.A.; Nair, S.B.; Badiger, M.V.; Kurungot, S. An all-solid-state-supercapacitor possessing a non-aqueous gel polymer electrolyte prepared using a UV-assisted in situ polymerization strategy. J. Mater. Chem. A 2017, 5, 8461-8476. [CrossRef]

127. Cho, Y.G.; Hwang, C.; Cheong, D.S.; Kim, Y.S.; Song, H.K. Gel/Solid Polymer Electrolytes Characterized by In Situ Gelation or Polymerization for Electrochemical Energy Systems. Adv. Mater. 2019, 31, 1804909. [CrossRef] [PubMed]

128. Liu, Z.X.; Liang, G.J.; Zhan, Y.X.; Li, H.F.; Wang, Z.F.; Ma, L.T.; Wang, Y.K.; Niu, X.R.; Zhi, C.Y. A soft yet device-level dynamically super-tough supercapacitor enabled by an energy-dissipative dual-crosslinked hydrogel electrolyte. Nano Energy 2019, 58, 732-742. [CrossRef]

129. Wang, Z.F.; Li, H.F.; Tang, Z.J.; Liu, Z.X.; Ruan, Z.H.; Ma, L.T.; Yang, Q.; Wang, D.H.; Zhi, C.Y. Hydrogel Electrolytes for Flexible Aqueous Energy Storage Devices. Adv. Funct. Mater. 2018, 28, 1804560. [CrossRef]

130. Wang, S.; Hsia, B.; Carraro, C.; Maboudian, R. High-performance all solid-state micro-supercapacitor based on patterned photoresist-derived porous carbon electrodes and an ionogel electrolyte. J. Mater. Chem. A 2014, 2, 7997-8002. [CrossRef]

131. Liu, L.; Ye, D.; Yu, Y.; Liu, L.; Wu, Y. Carbon-based flexible micro-supercapacitor fabrication via mask-free ambient micro-plasmajet etching. Carbon 2017, 111, 121-127. [CrossRef]

132. Lee, H.U.; Jin, J.H.; Kim, S.W. Effect of gel electrolytes on the performance of a minimized flexible micro-supercapacitor based on graphene/PEDOT composite using pen lithography. J. Ind. Eng. Chem. 2019, 71, 184-190. [CrossRef]

133. Shi, F.Y.; Li, J.J.; Xiao, J.T.; Zhao, X.Y.; Li, H.S.; An, Q.D.; Zhai, S.R.; Wang, K.; Wei, L.; Tong, Y. Three-dimensional hierarchical porous lignin-derived carbon/WO3 for high-performance solid-state planar micro-supercapacitor. Int. J. Biol. Macromol. 2021, 190, 11-18. [CrossRef] [PubMed]

134. Bu, F.; Zhou, W.W.; Xu, Y.H.; Du, Y.; Guan, C.; Huang, W. Recent developments of advanced micro-supercapacitors: Design, fabrication and applications. Npj Flex. Electron. 2020, 4, 31. [CrossRef]

135. Huang, P.; Lethien, C.; Pinaud, S.; Brousse, K.; Laloo, R.; Turq, V.; Respaud, M.; Demortiere, A.; Daffos, B.; Taberna, P.L.; et al. On-chip and freestanding elastic carbon films for micro-supercapacitors. Science 2016, 351, 691-695. [CrossRef] [PubMed]

136. Hsia, B.; Marschewski, J.; Wang, S.; In, J.B.; Carraro, C.; Poulikakos, D.; Grigoropoulos, C.P.; Maboudian, R. Highly flexible, all solid-state micro-supercapacitors from vertically aligned carbon nanotubes. Nanotechnology 2014, 25, 055401. [CrossRef]

137. Ouendi, S.; Robert, K.; Stievenard, D.; Brousse, T.; Roussel, P.; Lethien, C. Sputtered tungsten nitride films as pseudocapacitive electrode for on chip micro-supercapacitors. Energy Storage Mater. 2019, 20, 243-252. [CrossRef]

138. Li, J.H.; Zhu, M.J.; An, Z.L.; Wang, Z.Q.; Toda, M.; Ono, T. Constructing in-chip micro-supercapacitors of 3D graphene nanowall/ruthenium oxides electrode through silicon-based microfabrication technique. J. Power Sources 2018, 401, 204-212. [CrossRef]

139. Robert, K.; Douard, C.; Demortiere, A.; Blanchard, F.; Roussel, P.; Brousse, T.; Lethien, C. On Chip Interdigitated MicroSupercapacitors Based on Sputtered Bifunctional Vanadium Nitride Thin Films with Finely Tuned Inter- and Intracolumnar Porosities. Adv. Mater. Technol. 2018, 3, 1800036. [CrossRef]

140. Jhao, J.J.; Lin, C.H.; Yeh, T.K.; Wu, H.C.; Tsai, M.C.; Hsieh, C.K. The coaxial nanostructure of ruthenium oxide thin films coated onto the vertically grown graphitic nanofibers for electrochemical supercapacitor. Surf. Coat. Technol. 2017, 320, 263-269. [CrossRef]

141. Maphiri, V.M.; Rutavi, G.; Sylla, N.F.; Adewinbi, S.A.; Fasakin, O.; Manyala, N. Novel Thermally Reduced Graphene Oxide Microsupercapacitor Fabricated via Mask-Free AxiDraw Direct Writing. Nanomater. Basel 2021, 11, 1909. [CrossRef]

142. Shen, C.W.; Wang, X.H.; Li, S.W.; Wang, J.G.; Zhang, W.F.; Kang, F.Y. A high-energy-density micro supercapacitor of asymmetric $\mathrm{MnO} 2$-carbon configuration by using micro-fabrication technologies. J. Power Sources 2013, 234, 302-309. [CrossRef]

143. Dinh, T.M.; Mesnilgrente, F.; Conedera, V.; Kyeremateng, N.A.; Pech, D. Realization of an Asymmetric Interdigitated Electrochemical Micro-Capacitor Based on Carbon Nanotubes and Manganese Oxide. J. Electrochem. Soc. 2015, 162, A2016-A2020. [CrossRef] 
144. Niu, Z.Q.; Zhang, L.; Liu, L.; Zhu, B.W.; Dong, H.B.; Chen, X.D. All-Solid-State Flexible Ultrathin Micro-Supercapacitors Based on Graphene. Adv. Mater. 2013, 25, 4035-4042. [CrossRef]

145. Shen, B.S.; Lang, J.W.; Guo, R.S.; Zhang, X.; Yan, X.B. Engineering the Electrochemical Capacitive Properties of Microsupercapacitors Based on Graphene Quantum Dots $/ \mathrm{MnO}_{2}$ Using Ionic Liquid Gel Electrolytes. Acs Appl. Mater. Inter. 2015, 7, $25378-25389$. [CrossRef] [PubMed]

146. Huang, P.H.; Pech, D.; Lin, R.Y.; McDonough, J.K.; Brunet, M.; Taberna, P.L.; Gogotsi, Y.; Simon, P. On-chip micro-supercapacitors for operation in a wide temperature range. Electrochem. Commun. 2013, 36, 53-56. [CrossRef]

147. Soam, A.; Kavle, P.; Kumbhar, A.; Dusane, R.O. Performance enhancement of micro-supercapacitor by coating of graphene on silicon nanowires at room temperature. Curr. Appl. Phys. 2017, 17, 314-320. [CrossRef]

148. Jin, E.M.; Lee, H.J.; Jun, H.B.; Jeong, S.M. Electrochemical properties of alpha-Co(OH)(2)/graphene nano-flake thin film for use as a hybrid supercapacitor. Korean J. Chem. Eng. 2017, 34, 885-891. [CrossRef]

149. Zhou, J.H.; Chen, N.N.; Ge, Y.; Zhu, H.L.; Feng, X.M.; Liu, R.Q.; Ma, Y.W.; Wang, L.H.; Hou, W.H. Flexible all-solid-state micro-supercapacitor based on Ni fiber electrode coated with $\mathrm{MnO}_{2}$ and reduced graphene oxide via electrochemical deposition. Sci. China Mater. 2018, 61, 243-253. [CrossRef]

150. Zhao, D.W.; Chen, C.J.; Zhang, Q.; Chen, W.S.; Liu, S.X.; Wang, Q.W.; Liu, Y.X.; Li, J.; Yu, H.P. High Performance, Flexible, Solid-State Supercapacitors Based on a Renewable and Biodegradable Mesoporous Cellulose Membrane. Adv. Energy Mater. 2017, 7, 1700739. [CrossRef]

151. Xu, J.; Shen, G.Z. A flexible integrated photodetector system driven by on-chip microsupercapacitors. Nano Energy 2015, 13, 131-139. [CrossRef]

152. Yun, J.; Lim, Y.; Lee, H.; Lee, G.; Park, H.; Hong, S.Y.; Jin, S.W.; Lee, Y.H.; Lee, S.S.; Ha, J.S. A Patterned Graphene/ZnO UV Sensor Driven by Integrated Asymmetric Micro-Supercapacitors on a Liquid Metal Patterned Foldable Paper. Adv. Funct. Mater. 2017, 27, 1700135. [CrossRef]

153. Jiang, Q.; Wu, C.S.; Wang, Z.J.; Wang, A.C.; He, J.H.; Wang, Z.L.; Alshareef, H.N. MXene electrochemical microsupercapacitor integrated with triboelectric nanogenerator as a wearable self-charging power unit. Nano Energy 2018, 45, 266-272. [CrossRef]

154. Wang, S.; Wu, Z.S.; Zheng, S.H.; Zhou, F.; Sun, C.L.; Cheng, H.M.; Bao, X.H. Scalable Fabrication of Photochemically Reduced Graphene-Based Monolithic Micro-Supercapacitors with Superior Energy and Power Densities. ACS Nano 2017, 11, 4283-4291. [CrossRef] [PubMed]

155. Kim, S.W.; Kang, K.N.; Min, J.W.; Jang, J.H. Plotter-assisted integration of wearable all-solid-state micro-supercapacitors. Nano Energy 2018, 50, 410-416. [CrossRef]

156. Boruah, B.D.; Nandi, S.; Misra, A. Layered Assembly of Reduced Graphene Oxide and Vanadium Oxide Heterostructure Supercapacitor Electrodes with Larger Surface Area for Efficient Energy-Storage Performance. ACS Appl. Energy Mater. 2018, 1, 1567-1574. [CrossRef]

157. Jiang, Q.; Kurra, N.; Maleski, K.; Lei, Y.J.; Liang, H.F.; Zhang, Y.Z.; Gogotsi, Y.; Alshareef, H.N. On-Chip MXene Microsupercapacitors for AC-Line Filtering Applications. Adv. Energy Mater. 2019, 9, 1901061. [CrossRef]

158. Couly, C.; Alhabeb, M.; Van Aken, K.L.; Kurra, N.; Gomes, L.; Navarro-Suarez, A.M.; Anasori, B.; Alshareef, H.N.; Gogotsi, Y. Asymmetric Flexible MXene-Reduced Graphene Oxide Micro-Supercapacitor. Adv. Electron. Mater. 2018, 4, 1700339. [CrossRef]

159. Kim, D.; Lee, G.; Kim, D.; Ha, J.S. Air-Stable, High-Performance, Flexible Microsupercapacitor with Patterned lonogel Electrolyte. ACS Appl. Mater. Inter. 2015, 7, 4608-4615. [CrossRef] [PubMed]

160. Huang, J.J.; Hsueh, Y.L.; Zhang, Y.X. Silver nanowire doped active carbon thin film electrode by ultrasonic spray coating for high performance supercapacitor. Surf. Coat. Technol. 2018, 350, 788-794. [CrossRef]

161. He, Y.F.; Zhang, P.P.; Wang, F.X.; Wang, L.X.; Su, Y.Z.; Zhang, F.; Zhuang, X.D.; Feng, X.L. Vacancy modification of Prussian-blue nano-thin films for high energy-density micro-supercapacitors with ultralow RC time constant. Nano Energy 2019, 60, 8-16. [CrossRef]

162. Boruah, B.D.; Maji, A.; Misra, A. Flexible Array of Microsupercapacitor for Additive Energy Storage Performance Over a Large Area. ACS Appl Mater. Inter. 2018, 10, 15864-15872. [CrossRef] [PubMed]

163. Yin, J.; Kim, J.; Lee, H.U.; Park, J.Y. Highly conductive and flexible thin film electrodes based on silver nanowires wrapped carbon fiber networks for supercapacitor applications. Thin Solid Film. 2018, 660, 564-571. [CrossRef]

164. Liu, Z.Y.; Liu, S.H.; Dong, R.H.; Yang, S.; Lu, H.; Narita, A.; Feng, X.L.; Mullen, K. High Power In-Plane Micro-Supercapacitors Based on Mesoporous Polyaniline Patterned Graphene. Small 2017, 13, 1603388. [CrossRef] [PubMed]

165. Qin, J.Q.; Wang, S.; Zhou, F.; Das, P.; Zheng, S.H.; Sun, C.L.; Bao, X.H.; Wu, Z.S. 2D mesoporous $\mathrm{MnO}_{2}$ nanosheets for high-energy asymmetric micro-supercapacitors in water-in-salt gel electrolyte. Energy Storage Mater. 2019, 18, 397-404. [CrossRef]

166. Zheng, S.H.; Ma, J.M.; Wu, Z.S.; Zhou, F.; He, Y.B.; Kang, F.Y.; Cheng, H.M.; Bao, X.H. All-solid-state flexible planar lithium ion micro-capacitors. Energy Environ. Sci. 2018, 11, 2001-2009. [CrossRef]

167. Zhou, F.; Huang, H.B.; Xiao, C.H.; Zheng, S.H.; Shi, X.Y.; Qin, J.Q.; Fu, Q.; Bao, X.H.; Feng, X.L.; Mullen, K.; et al. Electrochemically Scalable Production of Fluorine-Modified Graphene for Flexible and High-Energy Ionogel-Based Microsupercapacitors. J. Am. Chem. Soc. 2018, 140, 8198-8205. [CrossRef] [PubMed]

168. Tian, W.Q.; Vahid Mohammadi, A.; Reid, M.S.; Wang, Z.; Ouyang, L.Q.; Erlandsson, J.; Pettersson, T.; Wagberg, L.; Beidaghi, M.; Hamedi, M.M. Multifunctional Nanocomposites with High Strength and Capacitance Using 2D MXene and 1D Nanocellulose. Adv. Mater. 2019, 31, 1902977. [CrossRef] [PubMed] 
169. Dong, Y.; Wang, L.; Ban, L.; Du, W.; Feng, X.J.; Chen, P.; Xiao, F.; Wang, S.; Liu, B.F. Selective vacuum filtration-induced microelectrode patterning on paper for high-performance planar microsupercapacitor. J. Power Sources 2018, 396, 632-638. [CrossRef]

170. Lu, Y.C.; Zheng, Y.W.; Zhang, H.; He, X.X.; Yang, Q.Q.; Wu, J. A high performance and flexible in-plane asymmetric microsupercapacitor (MSC) fabricated with functional electrochemical-exfoliated graphene. J. Electroanal. Chem. 2020, 866, 114169. [CrossRef]

171. Cai, J.G.; Lv, C.; Watanabe, A. Laser direct writing of high-performance flexible all-solid-state carbon micro-supercapacitors for an on-chip self-powered photodetection system. Nano Energy 2016, 30, 790-800. [CrossRef]

172. Huang, H.C.; Chung, C.J.; Hsieh, C.T.; Kuo, P.L.; Teng, H.S. Laser fabrication of all-solid-state microsupercapacitors with ultrahigh energy and power based on hierarchical pore carbon. Nano Energy 2016, 21, 90-105. [CrossRef]

173. Yadav, P.; Basu, A.; Suryawanshi, A.; Game, O.; Ogale, S. Highly Stable Laser-Scribed Flexible Planar Microsupercapacitor Using Mushroom Derived Carbon Electrodes. Adv. Mater. Interfaces 2016, 3, 1600057. [CrossRef]

174. El-Kady, M.F.; Strong, V.; Dubin, S.; Kaner, R.B. Laser Scribing of High-Performance and Flexible Graphene-Based Electrochemical Capacitors. Science 2012, 335, 1326-1330. [CrossRef]

175. El-Kady, M.F.; Kaner, R.B. Scalable fabrication of high-power graphene micro-supercapacitors for flexible and on-chip energy storage. Nat. Commun. 2013, 4, 2446. [CrossRef] [PubMed]

176. Kumar, R.; Savu, R.; Joanni, E.; Vaz, A.R.; Canesqui, M.A.; Singh, R.K.; Timm, R.A.; Kubota, L.T.; Moshkalev, S.A. Fabrication of interdigitated micro-supercapacitor devices by direct laser writing onto ultra-thin, flexible and free-standing graphite oxide films. Rsc Adv. 2016, 6, 84769-84776. [CrossRef]

177. Liu, Y.Q.; Weng, B.; Xu, Q.; Hou, Y.Y.; Zhao, C.; Beirne, S.; Shu, K.W.; Jalili, R.; Wallace, G.G.; Razal, J.M.; et al. Facile Fabrication of Flexible Microsupercapacitor with High Energy Density. Adv. Mater. Technol. 2016, 1, 1600166. [CrossRef]

178. Gao, J.; Shao, C.X.; Shao, S.X.; Wan, F.; Gao, C.; Zhao, Y.; Jiang, L.; Qu, L.T. Laser-Assisted Large-Scale Fabrication of All-Solid-State Asymmetrical Micro-Supercapacitor Array. Small 2018, 14, 1801809. [CrossRef] [PubMed]

179. Rao, Y.F.; Yuan, M.; Luo, F.; Wang, Z.P.; Li, H.; Yu, J.B.; Chen, X.P. One-step laser fabrication of phosphorus-doped porous graphene electrodes for high-performance flexible microsupercapacitor. Carbon 2021, 180, 56-66. [CrossRef]

180. Liang, H.F.; Ming, F.W.; Alshareef, H.N. Applications of Plasma in Energy Conversion and Storage Materials. Adv. Energy Mater. 2018, 8, 1801804. [CrossRef]

181. Wang, X.F.; Yin, Y.J.; Hao, C.L.; You, Z. A high-performance three-dimensional micro supercapacitor based on ripple-like ruthenium oxide-carbon nanotube composite films. Carbon 2015, 82, 436-445. [CrossRef]

182. Li, H.P.; Liang, J.J. Recent Development of Printed Micro-Supercapacitors: Printable Materials, Printing Technologies, and Perspectives. Adv. Mater. 2020, 32, 1805864. [CrossRef]

183. Zhang, Y.Z.; Wang, Y.; Cheng, T.; Yao, L.Q.; Li, X.C.; Lai, W.Y.; Huang, W. Printed supercapacitors: Materials, printing and applications. Chem. Soc. Rev. 2019, 48, 3229-3264. [CrossRef] [PubMed]

184. Wu, C.W.; Unnikrishnan, B.; Chen, I.W.P.; Harroun, S.G.; Chang, H.T.; Huang, C.C. Excellent oxidation resistive MXene aqueous ink for micro-supercapacitor application. Energy Storage Mater. 2020, 25, 563-571. [CrossRef]

185. Yu, L.H.; Fan, Z.D.; Shao, Y.L.; Tian, Z.N.; Sun, J.Y.; Liu, Z.F. Versatile N-Doped MXene Ink for Printed Electrochemical Energy Storage Application. Adv. Energy Mater. 2019, 9, 1901839. [CrossRef]

186. Wang, Y.; Zhang, Y.Z.; Dubbink, D.; ten Elshof, J.E. Inkjet printing of delta-MnO2 nanosheets for flexible solid-state microsupercapacitor. Nano Energy 2018, 49, 481-488. [CrossRef]

187. Brauniger, Y.; Lochmann, S.; Grothe, J.; Hantusch, M.; Kaskel, S. Piezoelectric Inkjet Printing of Nanoporous Carbons for Micro-supercapacitor Devices. ACS Appl. Energy Mater. 2021, 4, 1560-1567. [CrossRef]

188. Zhang, X.Y.; Zhao, W.; Wei, L.; Jin, Y.Y.; Hou, J.; Wang, X.X.; Guo, X. In-plane flexible solid-state microsupercapacitors for on-chip electronics. Energy 2019, 170, 338-348. [CrossRef]

189. Lee, S.S.; Choi, K.H.; Kim, S.H.; Lee, S.Y. Wearable Supercapacitors Printed on Garments. Adv. Funct. Mater. $2018,28,1705571$. [CrossRef]

190. Liu, L.; Lu, Q.; Yang, S.L.; Guo, J.; Tian, Q.Y.; Yao, W.J.; Guo, Z.H.; Roy, V.A.L.; Wu, W. All-Printed Solid-State Microsupercapacitors Derived from Self-Template Synthesis of Ag@PPy Nanocomposites. Adv. Mater. Technol. 2018, 3, 1700206. [CrossRef]

191. Chih, J.K.; Jamaluddin, A.; Chen, F.M.; Chang, J.K.; Su, C.Y. High energy density of all-screen-printable solid-state microsupercapacitors integrated by graphene/CNTs as hierarchical electrodes. J. Mater. Chem. A 2019, 7, 12779-12789. [CrossRef]

192. Li, H.P.; Li, X.R.; Liang, J.J.; Chen, Y.S. Hydrous $\mathrm{RuO}_{2}$-Decorated MXene Coordinating with Silver Nanowire Inks Enabling Fully Printed Micro-Supercapacitors with Extraordinary Volumetric Performance. Adv. Energy Mater. 2019, 9, 1803987. [CrossRef]

193. Bellani, S.; Petroni, E.; Castillo, A.E.D.; Curreli, N.; Martin-Garcia, B.; Oropesa-Nunez, R.; Prato, M.; Bonaccorso, F. Scalable Production of Graphene Inks via Wet-jet Milling Exfoliation for Screen-Printed Micro-Supercapacitors. Adv. Funct. Mater. 2019, 29, 1807659. [CrossRef]

194. Zhu, Y.G.; Wang, Y.; Shi, Y.M.; Wong, J.I.; Yang, H.Y. CoO nanoflowers woven by CNT network for high energy density flexible micro-supercapacitor. Nano Energy 2014, 3, 46-54. [CrossRef]

195. Tu, D.; Wu, Z.K.; Xu, J.H.; Zhou, Y.J.; Yang, W.Y.; Yang, Y.J.; Zha, X.T.; Shi, L.W. Direct Assembly of 3D-BCN Microspheres as a Microsupercapacitor Electrode for Wearable Energy Storage. ACS Appl Mater. Inter. 2020, 12, 47416-47424. [CrossRef] 
196. Liang, Y.; Wang, S.Y.; Wang, Y.Z.; He, S.M.; Liu, Z.W.; Fu, Y.L.; Sun, Z.; Li, M.Y.; Wu, Z.S.; Yu, H.J. Solid-state integrated micro-supercapacitor array construction with low-cost porous biochar. Mater. Chem. Front. 2021, 5, 4772-4779. [CrossRef]

197. Zhang, C.F.; Kremer, M.P.; Seral-Ascaso, A.; Park, S.H.; McEvoy, N.; Anasori, B.; Gogotsi, Y.; Nicolosi, V. Stamping of Flexible, Coplanar Micro-Supercapacitors Using MXene Inks. Adv. Funct. Mater. 2018, 28, 1705506. [CrossRef]

198. Gao, C.; Gao, J.; Shao, C.X.; Xiao, Y.K.; Zhao, Y.; Qu, L.T. Versatile origami micro-supercapacitors array as a wind energy harvester. J. Mater. Chem. A 2018, 6, 19750-19756. [CrossRef]

199. Liu, Y.Q.; Zhang, B.B.; Xu, Q.; Hou, Y.Y.; Seyedin, S.; Qin, S.; Wallace, G.G.; Beirne, S.; Razal, J.M.; Chen, J. Development of Graphene Oxide/Polyaniline Inks for High Performance Flexible Microsupercapacitors via Extrusion Printing. Adv. Funct. Mater. 2018, 28, 1706592. [CrossRef]

200. Zhang, C.F.; McKeon, L.; Kremer, M.P.; Park, S.H.; Ronan, O.; Seral-Ascaso, A.; Barwich, S.; Coileain, C.O.; McEvoy, N.; Nerl, H.C.; et al. Additive-free MXene inks and direct printing of micro-supercapacitors. Nat. Commun. 2019, 10, 1795. [CrossRef]

201. Fu, K.; Wang, Y.B.; Yan, C.Y.; Yao, Y.G.; Chen, Y.A.; Dai, J.Q.; Lacey, S.; Wang, Y.B.; Wan, J.Y.; Li, T.; et al. Graphene Oxide-Based Electrode Inks for 3D-Printed Lithium-Ion Batteries. Adv. Mater. 2016, 28, 2587-2594. [CrossRef] [PubMed]

202. Shen, K.; Ding, J.W.; Yang, S.B. 3D Printing Quasi-Solid-State Asymmetric Micro-Supercapacitors with Ultrahigh Areal Energy Density. Adv. Energy Mater. 2018, 8, 1800408. [CrossRef]

203. Tang, X.W.; Zhou, H.; Cai, Z.C.; Cheng, D.D.; He, P.S.; Xie, P.W.; Zhang, D.; Fan, T.X. Generalized 3D Printing of Graphene-Based Mixed-Dimensional Hybrid Aerogels. ACS Nano 2018, 12, 3502-3511. [CrossRef]

204. Chang, P.; Mei, H.; Zhou, S.X.; Dassios, K.G.; Cheng, L.F. 3D printed electrochemical energy storage devices. J. Mater. Chem. A 2019, 7, 4230-4258. [CrossRef]

205. Yang, W.J.; Yang, J.; Byun, J.J.; Moissinac, F.P.; Xu, J.Q.; Haigh, S.J.; Domingos, M.; Bissett, M.A.; Dryfe, R.A.W.; Barg, S. 3D Printing of Freestanding MXene Architectures for Current-Collector-Free Supercapacitors. Adv. Mater. 2019, 31, 1902725. [CrossRef]

206. Li, W.B.; Li, Y.H.; Su, M.; An, B.X.; Liu, J.; Su, D.; Li, L.H.; Li, F.Y.; Song, Y.L. Printing assembly and structural regulation of graphene towards three-dimensional flexible micro-supercapacitors. J. Mater. Chem. A 2017, 5, 16281-16288. [CrossRef]

207. Tian, X.C.; Jin, J.; Yuan, S.Q.; Chua, C.K.; Tor, S.B.; Zhou, K. Emerging 3D-Printed Electrochemical Energy Storage Devices: A Critical Review. Adv. Energy Mater. 2017, 7, 1700127. [CrossRef]

208. Zhang, F.; Wei, M.; Viswanathan, V.V.; Swart, B.; Shao, Y.Y.; Wu, G.; Zhou, C. 3D printing technologies for electrochemical energy storage. Nano Energy 2017, 40, 418-431. [CrossRef]

209. Yun, X.W.; Lu, B.C.; Xiong, Z.Y.; Jia, B.; Tang, B.; Mao, H.N.; Zhang, T.; Wang, X.G. Direct 3D printing of a graphene oxide hydrogel for fabrication of a high areal specific capacitance microsupercapacitor. Rsc Adv. 2019, 9, 29384-29395. [CrossRef]

210. Chen, Y.M.; Guo, M.H.; Xu, L.; Cai, Y.Y.; Tian, X.C.; Liao, X.B.; Wang, Z.Y.; Meng, J.S.; Hong, X.F.; Mai, L.Q. In-situ selective surface engineering of graphene micro-supercapacitor chips. Nano Res. 2022, 15, 1492-1499. [CrossRef] 